2012s-10

\title{
Substitution between bio-fuels and fossil fuels: is there a Green Paradox?
}

Quentin Grafton, Tom Kompas, Ngo Van Long

\begin{tabular}{c}
\hline Série Scientifique \\
Scientific Series
\end{tabular}

\author{
Montréal \\ Mai 2012
}

(C) 2012 Quentin Grafton, Tom Kompas, Ngo Van Long. Tous droits réservés. All rights reserved. Reproduction partielle permise avec citation du document source, incluant la notice (C).

Short sections may be quoted without explicit permission, if full credit, including (C) notice, is given to the source.
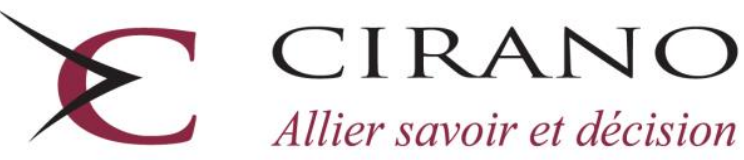

Allier savoir et décision

Centre interuniversitaire de recherche en analyse des organisations 


\section{CIRANO}

Le CIRANO est un organisme sans but lucratif constitué en vertu de la Loi des compagnies du Québec. Le financement de son infrastructure et de ses activités de recherche provient des cotisations de ses organisations-membres, d'une subvention d'infrastructure du Ministère du Développement économique et régional et de la Recherche, de même que des subventions et mandats obtenus par ses équipes de recherche.

CIRANO is a private non-profit organization incorporated under the Québec Companies Act. Its infrastructure and research activities are funded through fees paid by member organizations, an infrastructure grant from the Ministère du Développement économique et régional et de la Recherche, and grants and research mandates obtained by its research teams.

\section{Les partenaires du CIRANO}

\section{Partenaire majeur}

Ministère du Développement économique,

de l'Innovation et de l'Exportation

\section{Partenaires corporatifs}

Autorité des marchés financiers

Banque de développement du Canada

Banque du Canada

Banque Laurentienne du Canada

Banque Nationale du Canada

Banque Royale du Canada

Banque Scotia

Bell Canada

BMO Groupe financier

Caisse de dépôt et placement du Québec

\section{CSST}

Fédération des caisses Desjardins du Québec

Financière Sun Life, Québec

Gaz Métro

Hydro-Québec

Industrie Canada

Investissements PSP

Ministère des Finances du Québec

Power Corporation du Canada

Rio Tinto Alcan

State Street Global Advisors

Transat A.T.

Ville de Montréal

\section{Partenaires universitaires}

École Polytechnique de Montréal

HEC Montréal

McGill University

Université Concordia

Université de Montréal

Université de Sherbrooke

Université du Québec

Université du Québec à Montréal

Université Laval

Le CIRANO collabore avec de nombreux centres et chaires de recherche universitaires dont on peut consulter la liste sur son site web.

Les cahiers de la série scientifique (CS) visent à rendre accessibles des résultats de recherche effectuée au CIRANO afin de susciter échanges et commentaires. Ces cahiers sont écrits dans le style des publications scientifiques. Les idées et les opinions émises sont sous l'unique responsabilité des auteurs et ne représentent pas nécessairement les positions du CIRANO ou de ses partenaires.

This paper presents research carried out at CIRANO and aims at encouraging discussion and comment. The observations and viewpoints expressed are the sole responsibility of the authors. They do not necessarily represent positions of CIRANO or its partners. 


\title{
Substitution between bio-fuels and fossil fuels: is there a Green Paradox?
}

\author{
Quentin Grafton ${ }^{*}$, Tom Kompas ${ }^{\dagger}$, Ngo Van Long ${ }^{*}$
}

\begin{abstract}
Résumé / Abstract
Nous montrons que (i) la subvention de la production d'énergie renouvelable avec l'intention d'encourager la substitution des combustibles fossiles pourrait accentuer les dommages du changement climatique en accélérant l'extraction des combustibles fossiles, et que (ii) ce résultat est renversé dans certaines conditions spécifiées. Nous nous concentrons sur le cas des subventions pour des ressources renouvelables produites dans le cadre des coûts marginaux croissants, et supposons que les ressources renouvelables et les carburants fossiles sont actuellement en cours d'utilisation. Ces subventions ont un effet direct et un effet indirect dans des directions opposées. L'effet direct est la réduction de la demande de combustibles fossiles à un prix donné. L'effet indirect est la réduction du prix d'équilibre actuelle de carburants fossiles, ce qui tend à augmenter la demande de combustibles fossiles. La somme des deux effets peut avancer ou retarder la date de l'épuisement du stock de ressources nonrenouvelables selon la courbure de la courbe de la demande d'énergie et de la courbe d'offre pour le substitut renouvelable.
\end{abstract}

Mots clés : Subvention des ressources renouvelables; le Paradoxe Vert ; changements climatiques.

We show that (i) subsidies for renewable energy policies with the intention of encouraging substitution away from fossil fuels may accentuate climate change damages by hastening fossil fuel extraction, and that (ii) the opposite result holds under some specified conditions. We focus on the case of subsidies for renewable resources produced under increasing marginal costs, and assume that both the renewable resources and the fossil fuels are currently in use. Such subsidies have a direct effect and an indirect effect working in opposite directions. The direct effect is the reduction in demand for fossil fuels at any given price. The indirect effect is the reduction in the current equilibrium price for fossil fuels, which tends to increase the amount of fossil fuels demanded. Whether the sum of the two effects will actually result in an earlier or later date of exhaustion of the stock of fossil fuels depends on the curvature of the demand curve for energy and of the supply curve for the renewable substitute.

Keywords: Subsidies of renewable energy; the Green Paradox; climate change.

Codes JEL: Q54, Q42, Q30

\footnotetext{
* Crawford School of Government, Australian National University. Email: Quentin.grafton@anu.edu.au

† Crawford School of Government, Australian National University. Email: Tom.Kompas@anu.edu.au

$₫$ CIRANO ,CESifo, and Department of Economics, McGill University, 855 Sherbrooke St West, Montreal, H3A 2T7, Canada. Email: ngo.long@mcgill.ca
} 


\section{Introduction}

The need to reduce $\mathrm{CO}_{2}$ emissions to combat climate change is widely acknowledged. According to standard economic theory the first best measure would be a carbon tax, and, as Hoel (2011) succintly stated, "at any time, the optimal price of carbon emissions should be equal to the present value of all future climate costs caused by present emissions, often called the social cost of carbon." In the real world, however, policy makers are faced with many constraints on the choice of policy instruments and their levels, and consequently first best policies cannot be implemented. Governments, in particular, face political opposition to the introduction of efficient carbon taxes.

A more politically acceptable time path of carbon taxes would be of the "ramp" variety: a government starts with a low tax rate, but commits to raise the tax to efficient levels in the future. As has been demonstrated (e.g. Sinn, 2008a), such time paths of carbon tax may induce profit-maximizing fossil resource owners to hasten the extraction of their resources, thus increasing carbon emissions in the near term. ${ }^{1}$ Such an outcome has been termed a "Green Paradox" (Sinn, 2008b, 2012). Sinn's message is that in designing policies one must take into account supply responses by owners of fossil fuels.

The link between climate change and the behavior of firms extracting fossil-fuel resources was explored by Sinclair (1992,1994), Ulph and Ulph (1994), Hoel and Kverndokk (1996), Farzin and Tahvonen (1996), and Tahvonen (1997). Sinclair (1992) was among the first economists to explicitly consider climate change policies that would influence the extraction path of fossil fuels, stressing that "the key decision of those lucky enough to own oil-wells is not so much how much to produce as when to extract it." Strand (2007) showed that a technological agreement that makes carbon redundant in the future may increase current emissions. As pointed out by Hoel (2008), prior to 2008, there is little work making the link between climate policies and exhaustible resources when policies are non-optimal or

\footnotetext{
${ }^{1}$ Long and Sinn (1985) offered an analysis of how extractive firms respond to an anticipated time path of varying tax rate, but they did not explicitly mention the effect on $\mathrm{CO}_{2}$ concentration levels.
} 
international agreements are incomplete. ${ }^{2}$ Recent dynamic models that depict the adverse response of resource extracting firms to anticipation of taxes or substitute production include Sinn (2008a,b), Hoel (2008), Di Maria et al. (2008), Gerlagh and Liski (2008), Smulders et al. (2009), and Eichner and Pethig (2010). Hoel (2008) assumes that carbon resources remain cheaper than the substitute and analyses the situation where different countries have climate policies of different ambition levels. He shows that, in the absence of an efficient global climate agreement, climate costs may increase as a consequence of improved technology of substitute production. Hoel $(2010,2011)$ uses a two-period model where firms invest in capacity of producing a substitute. A number of key parameters are considered in his model (e.g. a parameter to capture how rapidly extraction costs increase with increasing total extraction, and a parameter affecting the time profile of the returns to investments in the substitute). Whether an investment subsidy results in greater environmental damages (a Green Paradox) depends on the relationship among these parameters.

Gerlagh (2011) considers a model where extraction cost is constant, and a backstop technology can produce unlimited amount of a renewable substitute, at a constant cost per unit. He defines a Weak Green Paradox as an increase in the current emissions in response to an improvement in the backstop technology, and a Strong Green Paradox when the net present value of damages increases as a result of an improvement in the backstop technology. Ploeg and Withagen (2010) focus on the case where marginal extraction costs of the exhaustible resource depend on the existing stock. They assume that the substitute is available in unlimited supply at a constant marginal cost. After characterizing the social optimum, they turn to the case where first-best policies are not feasible, and show that the Green Paradox prevails if the cost of backstop decreases, provided that the backstop remains expensive such that the non-renewable resource stock is eventually exhausted. By contrast, if the backstop becomes so cheap that physical exhaustion will not take place, the Green Paradox no longer holds.

\footnotetext{
${ }^{2}$ See Bohm (1994) and Hoel (1994) for static models along these lines.
} 
The bulk of the theoretical literature on substitute production assumes that a renewable substitute can be produced under constant marginal cost. In that setting, assuming also a constant cost of extraction of fossil fuels, the Green Paradox outcome is inevitable. The intuition behind this inevitability of the Green Paradox is that subsidies on the backstop technology leads to a lower peak price for fossil fuels, whose fixed stock must be exhausted before the renewable is produced.This implies that the whole time path of fossil fuel price is shifted downward, resulting in greater consumption of fossil fuels earlier on. ${ }^{3}$ It is important to emphasize that in such models fuel consumption has two distinct phases: in the first phase, only the exhaustible resource is used, and in the second phase, only the renewable substitute is used. By construction, there is no phase where both resources are consumed simultaneously. The key assumption which is responsible for the absence of simultaneous use is that the renewable substitute is produced at constant unit cost.

In reality, renewable substitutes such as biofuels are produced under conditions of increasing marginal cost. As pointed out in Chakravorty et al. (2011), increased use of biofuel may, by moving up the supply curve of land, increase the unit cost of the renewable resource. Using an dynamic empirical model firmly grounded on the Hotelling framework, they estimated the effect of biofuel mandates on food prices. They did not address the issue of the Green Paradox. With a few exceptions, the bulk of the existing literature on biofuel subsidies uses static analysis. Many authors have found, in the static context, mechanisms for increased carbon emissions (a Green Paradox outcome) with biofuel subsidies. ${ }^{4}$ It has also been pointed out that the production process of biofuels is not "green" because it involves the use of many inputs with high carbon contents. Moreover, because the first generation of biofuels displace land for food production it may increase food prices.

Our paper complements the existing literature with a dynamic mechanism. The contri-

\footnotetext{
${ }^{3}$ See Dasgupta and Heal (1979). Pearce and Turner (1990) provide a good exposition. Earlier models of substitute production include Heal $(1976)$ and Hoel $(1978,1983)$, which, though not dealing with $\mathrm{CO}_{2}$ emissions, contain all the ingredients from which one can deduce a Green Paradox result.

${ }^{4}$ For static analysis of energy substitution, see Hill et al. (2006), Steenblik (2007), Koplow (2007), Lapan and Moschini (2009), Bandyopadhyay et al. (2009), Moschini et al. (2010). Bahel et al. (2011) developed a dynamic model but their focus was on food prices.
} 
bution is a much richer understanding of the Green Paradox, delimiting cases when it occurs and when it does not, and shedding light on the inter-temporal consequences of biofuels subsidies. ${ }^{5}$ While models without a phase of simultaneous consumption are useful devices to illustrate principles, it is also important to consider situations where there is a phase in which exhaustible resources and renewable substitutes are simultaneously consumed in varying proportions. Such situations occur when the renewable substitute is produced under increasing marginal cost. This corresponds to the case of first generation biofuels based on conventional crops such as sugar cane, corn and vegetable oils (soy, canola, etc.). This is because the gradual expansion biofuels output, at least for first generation biofuels, necessitates the increasing use of less productive land with inevitable diminishing returns. ${ }^{6}$

Using a framework where both types of fuels are simultaneously consumed in the first phase phase, we find conditions under which a Green Paradox outcome will not occur, as well as conditions under which it will occur. We focus on the effect of a biofuel subsidy on the time path of extraction of the fossil fuel resources. A striking result of our paper is that in the case of a linear demand for energy, together with (i) zero extraction cost for fossil fuels and (ii) an upward-sloping linear marginal cost of biofuels, a biofuel subsidy will have no effect on the amount of fossil fuels extracted at each point of time, even though the subsidy does result in a lowering of the price of both fuels at each point of time, and in a higher quantity of energy demanded at each point of time. Under the stated assumptions we show that the increase in quantity of fuel demanded is exactly matched by an increased output of biofuels, leaving the extraction rate unchanged. Thus, the time at which the stock of fossil fuels is exhausted is unchanged, irrespective of the rate of subsidy. This result stands in constrast to the inevitable Green Paradox in the model of Hoel (2008) where the supply

\footnotetext{
${ }^{5}$ Fischer and Salant (2012) examined the Green Paradox in the presence of a subsidy for renewable resources. However, unlike our model, they assumed that the unit cost of renewable is constant in any given period. Their formulation allows unit cost to fall over time through knowledge accumulation. They found several cases where the Green Paradox may hold.

${ }^{6}$ To completely replace fossil fuels, humanity must make use of the whole range of alternative clean energy sources, including biofuels, geo-thermal heat, wind, solar, etc. As a referee points out, our paper may be regarded as dealing in general with renewables produced under increasing marginal costs. It is convenient to use of the expression "biofuels" as a catch-all term.
} 
curve of the renewable resource is horizontal. We stress that the Green Paradox does not arise in our model in the presence of a linear and increasing marginal cost of the renewable substitute to fossil fuels.

A second and important result of our paper is that when the assumption of zero extraction cost of the fossil fuel is replaced by the assumption of a positive and constant marginal extraction cost, a biofuel subsidy will result in a longer time over which the fossil fuel stock is exhausted. In this second case the Green Paradox does not arise. Indeed, there is no paradox at all: the subsidy works as intended because it extends the extraction period.

A third setting to investigate the possibility of a Green Paradox is when the marginal cost of biofuels increases at an increasing, or a decreasing rate as biofuels supply increases. In particular, we consider the case where the marginal cost of biofuel production is strictly increasing and strictly concave. In this situation along the equilibrium price path, as the price of energy rises gradually along the optimal extraction path of fossil fuels, biofuel output will increase over time, but the rate of the supply increase (per dollar increase in energy price) is greater when the price is higher. Consequently, fossil fuel firms, in anticipation of this greater expansion of the substitute in the later stage, respond by increasing their extraction at an earlier date. In this case, a Green Paradox outcome results.

In summary there are multiple cases when the Green Paradox does, and does not hold. The purpose of our analysis is to provide necessary and sufficient conditions for the Green Paradox to hold. We decompose the effect of a biofuel subsidy and show, for the first time, a direct effect of the subsidy (which is "pro-Green") and an indirect effect (which is "anti-Green"). Further, we show that a Green Paradox occurs if and only if the indirect effect outweights the direct effect. The analytical condition is general, but it can be hard to interpret without numerical examples. For this reason, we have supplied and commented on some simulation results.

Our model is consistent with the current state of play in terms of biofuel production. The main producing countries for transport biofuels are the U.S., Brazil and the EU. Brazil 
and the U.S. combined produced 55 and 35 percent, respectively, of the world's ethanol production in 2009 while the EU produced 60 percent of the total biodiesel output. The main stimulus to the use of biofuels are policies that encourage the substitution from fossil fuels, especially for road transportation. Government mandates for blending biofuels into vehicle fuels have also been enacted in at least 17 countries, and many states and provinces within these countries. Typical mandates require blending 10-15 percent ethanol with gasoline or blending 2-5 percent biodiesel with diesel fuel. Recent targets have encouraged higher levels of biofuel use in various countries (UNEP, 2009, page 15-16).

The range of policies that have stimulated biofuel demand by setting targets and blending quotas has been aided by supporting mechanisms, such as subsidies and tax exemptions. In the US, the total biofuels support encompasses the total value of all government supports to the biofuels industry, including consumption mandates, tax credits, import barriers, investment subsidies and general support to the sector such as public research investment. A report by Koplow (2007, pp. 29, 31) for the Global Subsidies Initiative indicates that the total support estimates for the US alone, in 2008, was between $\$ 9.2$ and 11.07 billion.

What do our results imply for biofuel subsidy policies? Our analysis indicates that the effects of proposed policies can only be gauged by using empirical models that are firmly grounded on dynamic theory that takes into account intertemporal behavior of resource extraction firms.

\section{A general model of simulataneous use of fossil fuels and biofuels}

Most of the literature on the Green Paradox that involves renewable substitutes is based on the assumption that the substitute is adopted only when the use of fossil fuels comes to an end. Thus a typical model displays two phases. In the first phase, only fossil fuels are consumed. In the second phase, the renewable substitute completely displaces the use of fossil fuels. These models are based on the assumption that the substitute is available in 
unlimited supply, at a constant unit cost.

In this paper, we focus on the case where both types of fuels are supplied in the market. This is made possible by postulating an upward sloping supply curve for biofuels. We allow this positive slope to be constant for all output levels, or to be increasing or decreasing (while still remaining positive) with output. Our assumptions on the cost of extraction of the fossil fuels allows for the possibility that as the stock dwindles, the extraction cost rises. The special case of stock-independent marginal cost is also admitted.

On the demand side, we assume that fossil fuels and biofuels are perfect substitutes: one unit of energy can be obtained from using one unit of fossil fuels, or alternatively one unit of biofuels. We denote by $P_{t}$ as the consumer's price of fuels at time $t$, and by $E_{t}^{d}$ the quantity of fuel demanded. The demand function is $E_{t}^{d}=D_{E}\left(P_{t}\right)$ where $D_{E}^{\prime}\left(P_{t}\right)<0$.

We assume that biofuel firms are price takers. Suppose that for each unit of biofuel sold, the biofuel producers receive $(1+v) P_{t}$ dollars, where $v$ is the ad valorem subsidy rate. (We may interpret $v$ as a production subsidy). Let $z=1+v$. We call $z$ the "subsidy factor." Let $B_{t}$ be the quantity of biofuels supplied at time $t$. The supply curve of biofuels is upward sloping, $B_{t}=S\left(z P_{t}\right)$, with $S^{\prime}(z P)>0$. We allow the second derivative $S^{\prime \prime}(z P)$ to be negative or positive. The special case $S^{\prime \prime}(z P)=0$ implies that the supply curve is linear.

Concerning the extraction of fossil fuels, we assume that the fossil fuels sector consists of $n$ identical producers, each having an initial stock $R_{i 0}$. Let $q_{i t}$ denote producer $i$ 's rate of extraction at time $t$, and $R_{i t}$ denote his remaning stock. Then $\dot{R}_{i t}=-q_{i t}$. Omitting the subscripts for simplicity, we write the extraction cost function for each firm as $C(q, R)$. We assume that (i) marginal extraction cost is non-negative, $C_{q} \geq 0$, and non-decreasing in extraction rate, $C_{q q} \geq 0$; (ii) the extraction cost is non-increasing in the size of the reserves, $C_{R} \leq 0$; (iii) as the stock dwindles, the marginal extraction cost rises (or remain constant), $C_{q R} \leq 0 .^{7}$

$$
C_{q} \geq 0, \quad C_{q q} \geq 0, \quad C_{R} \leq 0, \quad C_{q R} \leq 0
$$

\footnotetext{
${ }^{7}$ See e.g. Farzin (1992).
} 
Let $Q_{t}$ be the aggregate extraction of fossil fuels at time $t: Q_{t} \equiv \sum_{i=1}^{n} q_{i t}$.

By assumption fossil fuels and biofuels are perfect substitutes. Flow equilibrium in the fuel market, thus, requires that total supply (i.e., aggregate extraction $Q_{t}$ plus the output of biofuel producers, $B_{t}$ ) equals the quantity of fuels demanded, $E_{t}$ :

$$
Q_{t}+B_{t}=E_{t}
$$

This condition implies that

$$
Q_{t}=D_{E}\left(P_{t}\right)-S\left(z P_{t}\right)
$$

Let us define

$$
D\left(P_{t} ; z\right) \equiv D_{E}\left(P_{t}\right)-S\left(z P_{t}\right)
$$

The function $D\left(P_{t} ; z\right)$, defined as the difference between the demand for fuels and the supply of biofuels, is called the demand for fossil fuels. For any given $z>0$, there is a unique price $\bar{P}$ (which depends on $z$ ) at which $D(\bar{P} ; z)=0$. We call $\bar{P}$ the "choke price" for fossil fuels, where $D_{E}(\bar{P})-S(z \bar{P})=0$. When the price reaches $\bar{P}$, the entire market demand for fuels is met by biofuel producers. A higher $z$ implies a lower choke price:

$$
\frac{d \bar{P}}{d z}=\frac{S^{\prime}(z \bar{P}) \bar{P}}{D_{E}^{\prime}(\bar{P})-S^{\prime}(z \bar{P}) z}<0
$$

An increase in $z$ also has an effect on the demand for fossil fuels: at any price below the choke price, a higher $z$ implies a smaller quantity demanded (for fossil fuels). Figure 1 illustrates the effect of an increase in the subsidy factor $z$, from $z_{1}$ to $z_{2}>z_{1}$. We assume in the Figure that $S(0)=0$, but our mathematical analysis does not require this assumption.

\section{PLEASE PLACE FIGURE 1 HERE}

A higher biofuel production-subsidy implies that at any given consumer's price $P$, a greater quantity of biofuels is supplied. This is represented by a clockwise rotation of the biofuel supply curve in Figure 1. This rotation implies that the demand curve for fossil fuels, $D\left(P_{t} ; z\right)$, is rotated anti-clockwise, as is clear from equation (4). In Figure 1, this rotation is 
from $E M_{1}$ to $E M_{2}$. The old choke price $\bar{P}\left(z_{1}\right)$ is depicted by point $M_{1}$ and the new choke price $\bar{P}\left(z_{2}\right)$ is depicted by point $M_{2}$.

Figure 1 appears to indicate that a higher rate of biofuel subsidy will result in lower emissions, but this can only be true at a given price. For example, in Figure 1, at the given $P_{0}$, the direct effect of a biofuel production subsidy is to increase biofuel output from point $A$ to point $B$, implying that the quantity of fossil fuels demanded falls from $Y_{0}$ to $Y^{\prime}$. However, taking into account the full response of extractive firms, the equilibrium price $P_{0}$ would also change as a result of the increase in the subsidy rate. Thus, the extraction path of fossil fuels must, in general, be adjusted, and so must $P_{0}$ and all $P_{t}$, in order to ensure that: (i) the flow equilibrium condition (2) is satisfied at all points of time; (ii) the intertemporal equilibrium condition, known as the Hotelling Rule, is satisfied along a positive extraction path; and (iii) the stock equilibrium condition holds such that the cumulative extraction up to the exhaustion time $T$ should equal the initial stock. Consequently, the initial price must fall, for instance, from $P_{0}$ to, say, $P_{0}^{\prime}$ in Figure 1.

As the initial price falls from $P_{0}$ to $P_{0}^{\prime}$, the output of biofuel moves along the biofuel supply curve $S\left(z_{2} P\right)$ from point $B$ to point $N$, and thus the quantity demanded for fossil fuels rises. We call this the indirect effect of the biofuel subsidy. Figure 1 depicts a very special case where the fall in initial price is just sufficient to restore the initial quantity of fossil fuel demanded back to $Y_{0}$ (i.e. in this case the subsidy has no effect on the extraction rate of fossil fuels, because the direct effect and the indirect effect cancel each other out).

In what follows, we show how the equibrium paths of price and quantity would adjust to a permanent increase in the subsidy factor $z$. We consider two cases.

Case I (stock-independent extraction cost). In this case, $C_{R}=0$ for all $R$. Case II (stock-dependent extraction cost). In this case, $C_{q R}<0$.

In Case I, it is convenient to denote the marginal extraction cost by $c(q)$. Since $c(q)$ is assumed to be non-decreasing, marginal extraction cost is lowest when $q=0$. We assume that $c(0)$ is lower than the choke price $\bar{P}(z)$, so that the firm will find it optimal to (eventually) 
exhaust its stock.

In Case II, $C_{q}(0,0)$ is called the "marginal cost of extracting the last drop of oil." We distinguish two sub-cases. In sub-case II-A, $C_{q}(0,0) \leq \bar{P}(z)$, which implies that eventual exhaustion is optimal. In sub-case II-B, $C_{q}(0,0)>\bar{P}(z)$, the marginal cost of extracting the last drop of oil is high, and physical exhaustion will not take place. In sub-case II-B there exists a positive reserve level $R_{L}$ such that $C_{q}\left(0, R_{L}\right)=\bar{P}(z)$, and the firm will abandon its stock when the reserve level $R$ reaches $R_{L}$. This case involves economic exhaustion rather than physical exhaustion.

We now consider the optimization problem of the representative extractive firm. We assume it has perfect foresight of the price path, which it takes as given. It chooses the extraction path $q_{t}$, the terminal time $T$ and the terminal stock level $R_{T}$ to maximize

$$
\int_{0}^{T} e^{-r t}\left(q_{t} P_{t}-C\left(q_{t}, R_{t}\right)\right) d t
$$

where $r>0$ is the rate of interest. The necessary conditions yield the Hotelling equation

$$
\frac{d}{d t}\left[P_{t}-C_{q}\left(q_{t}, R_{t}\right)\right]=r\left(P_{t}-C_{q}\right)+C_{R} \text { for } 0 \leq t \leq T
$$

with $q_{T}=0$, and the transversality condition takes the form

$$
P_{T}-C_{q}\left(0, R_{T}\right) \geq 0, \quad R_{T} \geq 0, \quad\left[P_{T}-C_{q}\left(0, R_{T}\right)\right] R_{T}=0
$$

The transversality condition (7) is intuitively plausible. If it is optimal to leave some stock $R_{T}$ unexploited, it must be the case that at the terminal time $T$ the marginal cost of extraction equals the choke price. By contrast, if resource exhaustion is optimal, the terminal marginal extraction cost must generally be lower than the terminal price.

Given that all firms are identical, we focus on the symmetric equilibrium where $n q_{t}=$ $Q_{t}=D\left(P_{t} ; z\right)$. Differentiation with respect to time yields $\dot{Q}_{t}=D_{P}\left(P_{t} ; z\right) \dot{P}_{t}$. Substituting these two equations into the Hotelling Rule (6) gives us the evolution of the equilibrium price path:

$\dot{P}=r\left[P-C_{q}\left(\frac{D(P ; z)}{n}, R\right)\right]+C_{R}+C_{q q}\left(\frac{D(P ; z)}{n}, R\right) \frac{D_{P}(P ; z) \dot{P}}{n}-C_{q R}\left(\frac{D(P ; z)}{n}, R\right) \frac{D(P ; z)}{n}$ 
For given initial stock size $R_{0}$ and given $z$, this differential equation, together with $\dot{R}=$

$-\frac{D(P ; z)}{n}$ and condition (7), can be solved to determine the equilibrium paths of price, output, and the equilibrium terminal time $T$ at which $P_{T}=\bar{P}(z)$.

At the level of generality displayed by equation (8), it is not possible to determine the effect of an increase in the biofuel subsidy factor $z$ on the extraction path and the exhaustion time $T$. In the next section, we consider the case of stock-independent marginal cost, in which equation (8) reduces to a simpler form.

\section{The case of stock-independent marginal extraction cost}

Consider the special case where the marginal extraction cost is stock-independent and is a constant $c \geq 0$.Then $C(q, R)=c q$, and $C_{q}=c$. Assume $c<\bar{P}$, so that it is profitable to extract and to eventually exhaust the resource stock, i.e. $R_{T}=0$. Condition (8) reduces to $\dot{P}=r(P-c)$. This equation implies the following Hotelling price path for all $t \in[0, T]$ :

$$
P_{t}=c+(\bar{P}(z)-c) e^{r(t-T)} \equiv \phi(\bar{P}(z), t, T)
$$

This equation shows that the price at time $t$ is functionally related to the exhaustion time $T$ as well as the choke price $\bar{P}$. Note that $\phi$ is decreasing in $T$ and increasing in $\bar{P}$.

From equation (9) and the differential equation $\dot{R}_{t}=-D\left(P_{t} ; z\right) / n$ we obtain the stock equilibrium condition that accumulated extraction (from time zero to the exhaustion time) equals the initial reserves:

$$
\int_{0}^{T} D\left(c+(\bar{P}(z)-c) e^{r(t-T)} ; z\right) d t=-\int_{0}^{T} n \dot{R}(t) d t=n R_{0}
$$

Given $R_{0}$ and $z$, this equation uniquely determines the equilibrium exhaustion time $T$. If an increase in $z$ brings the exhaustion time $T$ closer to the present, we says that we obtain a Green Paradox. It is clear that if $T$ is brought closer to the present, the present value of the 
flow of damages will be greater, even though we have not explicitly modelled the relationship between the time path of damages and the time path of cumulative emissions. ${ }^{8}$

What are the forces that determine the net effect of an increase in the biofuel subsidy factor $z$ on the time of exhaustion $T$ ? We know from equation (5) that an increase in $z$ will lower the fossil fuel choke price $\bar{P}$. At the same time, an increase in $z$ rotates the demand curve for fossil fuel in the anti-clockwise direction, as shown in Figure 1. Does an increase in $z$ generate, on average, greater demand for fossil fuels over the time interval $T$ ? To answer this question, it is useful to decompose the change in demand into a direct effect and an indirect effect.

Direct Effect: The anti-clockwise rotation of the demand curve for fossil fuels implies that any given price $P_{t}$, the quantity demanded is smaller than before. This direct effect is capture by the term $D_{z}<0$. The direct effect is "pro-Green": an increase in biofuel subsidy reduces demand for fossil fuels, at any given price $P_{t}$.

Indirect Effect: The increase in $z$ (biofuel subsidy) lowers the fossil fuel choke price $\bar{P}$. This implies that, holding $T$ constant, the price $P_{t}$ must fall, see equation (9). A fall in $P_{t}$ increases the quantity demanded. The indirect effect, captured by the term $\left(\frac{\partial D}{\partial P_{t}}\right)\left(\frac{\partial P_{t}}{\partial z}\right)$, is positive, i.e. it is "anti-Green".

The total effect on fossil fuels consumption at any time $t$ is the sum of the direct effect and the indirect effect at that time. In general, the total effect can be positive at some points of time and negative at some other points of time. Therefore, to find the effect of biofuel subsidy, one has to compute the cumulative total effect, over the interval $[0, T]$. If this cumulative total effect is positive, it means that the exhaustion time must be brought closer to the present, which is a Green Paradox outcome. A more formal analysis follows.

To find the net effect of a change in $z$ on the exhaustion time $T$, let us write

$$
G(T, z)=\int_{0}^{T} D\left(c+(\bar{P}(z)-c) e^{r(t-T)} ; z\right) d t-n R_{0}=0
$$

\footnotetext{
${ }^{8}$ For the importance of cumulative emissions, see Allen et al. (2009). For additional considerations such as the feedback effects of temperature increases on GHGs emissions, see Winter (2011), among others.
} 
Then

$$
\frac{d T}{d z}=-\frac{G_{z}}{G_{T}}=\frac{-\int_{0}^{T}\left[D_{P} \frac{\partial P_{t}}{\partial z}+D_{z}\right] d t}{D(\bar{P}(z) ; z)+\int_{0}^{T}\left[D_{P} \frac{\partial P_{t}}{\partial T}\right] d t}
$$

where the denominator is positive because $D(\bar{P}(z) ; z)=0, D_{P}<0$ and $\partial P_{t} / \partial T<0$ from equation (9). The integrand in the numerator is ambiguous in sign:

$$
D_{z}+\left(D_{P} \frac{\partial P_{t}}{\partial z}\right) \lessgtr 0
$$

The comparative static expression (11) depends on the integral of the expression (12). Even though in general the sign of (12) is uncertain, the sign of its integral may be determinate or at least calculated numerically.

Lemma 1: An increase in the subsidy factor $z$ will bring the resource-exhaustion date $T$ closer to the present (i.e. will lower $T$ ) if and only if the cumulative indirect effect dominates the cumulative direct effect

$$
\int_{0}^{T} D_{P} \frac{\partial P_{t}}{\partial z} d t>\int_{0}^{T}\left(-D_{z}\right) d t
$$

Since in general we cannot determine the sign of $d T / d z$, we consider some special cases.

\subsection{Linear demand for energy and linear biofuel-supply function}

Assume that both the demand function for energy $D_{E}(P)$ and the biofuel supply function are linear, $D_{E}(P)=a-b P$, and $S(z P)=\beta z P-g$, where $a>0, b>0, \beta>0$ and $g \geq 0$. Then the (residual) demand function for fossil fuel is $D(P ; z)=(a+g)-b P-\beta z P$. From equation (9)

$$
P_{t}=c+(\bar{P}(z)-c) e^{r(t-T)}=c\left[1-e^{r(t-T)}\right]+\bar{P}(z) e^{r(t-T)}
$$

The direct effect is then

$$
D_{z}\left(P_{t} ; z\right)=-\beta P_{t}=-\beta \bar{P}(z) e^{r(t-T)}-\beta c\left[1-e^{r(t-T)}\right]<0
$$

To calculate the indirect effect, note that

$$
\bar{P}(z)=\frac{(a+g)}{b+\beta z} \Longrightarrow \frac{d \bar{P}}{d z}=-\frac{(a+g) \beta}{(b+\beta z)^{2}}<0 .
$$


and

$$
\partial P_{t} / \partial z=(d \bar{P} / d z) e^{r(t-T)}=-\frac{a \beta}{(b+\beta z)^{2}} e^{r(t-T)}=-\frac{\beta \bar{P}(z) e^{r(t-T)}}{b+\beta z}<0
$$

Then the indirect effect is

$$
D_{P} \frac{\partial P_{t}}{\partial z}=[(b+\beta z)]\left[\frac{\beta \bar{P}(z) e^{r(t-T)}}{b+\beta z}\right]=\beta \bar{P}(z) e^{r(t-T)}>0
$$

Comparing the direct effect (14) and the (15), we see that they cancel each other out if $c=0$. If $c>0$, then the direct effect dominates the indirect effect, and there is no Green Paradox. Thus, making use of Lemma 1, we can state the following result.

Proposition 1: Assume that the demand function for fuels and the supply function of biofuels are both linear. Then under perfectly competitive extraction, an increase in the subsidy for biofuel producers will generally delay the exhaustion date, i.e. $d T / d z \geq 0$. In particular,

(i) Assume extraction costs are zero $(c=0)$. Then an increase in the biofuel subsidy factor $z$ has no effect on the date of exhaustion of the resource stock. The cumulative extraction path under the biofuel subsidy is identical to the cumulative extraction path without the biofuel subsidy. (The direct effect and the indirect effect of an increase in z cancel each other out.)

(ii) Assume extraction costs are positive and smaller than the choke price $(\bar{P}>c>0)$. Then an increase in the biofuel subsidy factor $z$ leads to a delay the date of exhaustion of the resource stock. The cumulative extraction path with the biofuel subsidy is uniformly lower than the cumulative extraction path without the biofuel subsidy.

Remark 1. The intuition behind Proposition 1 is as follows. A permanent increase in biofuel subsidies at time $t=0$ creates a direct effect: increased biofuel production at any given price (a clockwise rotation of the biofuel supply cuve, see Figure 1). This increased supply of biofuels implies that if the price path for fuels were unchanged, less fossil fuels would be demanded at each point in time. Hence, if the price path were unchanged, the fossil fuel stock would not be exhausted by the time the price reaches the new (and lower) 
choke price, $M_{2}$ in Figure 1. But from our assumption that $c<M_{2}$ non-exhaustion cannot be an equilibrium. So the price at all $t$ must fall to stimulate demand for fuels (and hence for fossil fuels) sufficiently to clear the market. The fall in $P_{0}$ tends to reduce the amount of biofuels supplied (an induced effect, a movement along the already rotated biofuel supply curve, from point $B$ to point $N$ in Figure 1). At the lower price, the demand for energy is higher than in the no-subsidy scenario, and while some of this demand is met by biofuel production, the remaining demand is met by fossil fuel extraction. When $c=0$ and the demand and supply are linear, the fall in the initial price (from $P_{0}$ to $P_{0}^{\prime}$ ) is just sufficient for the flow demand for fossil fuels to be restored to the level that prevails in the no-subsidy scenario (point $Y_{0}$ in Figure 1). When $c>0$, the fall in initial price is smaller (above the point $P_{0}^{\prime}$ depicted in Figure 1), so the amount of fossil fuels demanded at time $t=0$ will be smaller than $Y_{0}$ in Figure 1.

Remark 2. We note the possibility that the direct and indirect effects perfectly offset each other. Such outcomes are also possible in different contexts, such as, in macroeconomics, with a logarithmic utility function an increase in the interest rate has no impact on savings because the income effect and the substitution effect cancel each other out.

Remark 3. Another interpretation of part (i) of Proposition 1 is as follows. Assume that the demand for an exhaustible resource is linear, $Q=a-(b+\beta z) P \equiv a-\widetilde{b} P$, and that extraction cost is zero. A rotation of the linear demand curve (keeping the horizontal intercept $a$ unchanged, while changing $\widetilde{b}$ ) will leave the equilibrium extraction path and the exhaustion time unchanged, but the equilibrium price path will be changed. Figure 2 shows the time paths of price for different values of $\widetilde{b}$, under the assumption that $c=0$. It is important to note that while superficially the time path of price in Figure 2 looks like the standard textbook figures which treat the case of a substitute that is available at constant cost and that is supplied only after extraction of fossil fuels has ceased, the underlying story is not the same because, in our case, both biofuels and fossil fuels are consumed simultaneously at each point of time, and the increased demand for fuels associated with the lower price path 
is satisfied by the expansion of biofuel output. This explains why in Figure 2 it is possible that the stock is exhausted at the same time $T$ even though the price path is lowered as the result of a subsidy.

\section{PLEASE PLACE FIGURE 2 HERE}

\subsection{Isoelastic biofuel-supply function and modified-isoelastic en- ergy demand function}

We now consider the special case where the biofuel supply function is isoelastic

$$
S(z P)=\beta(z P)^{\mu} \text { where } \beta>0 \text { and } \mu>0
$$

(where $\mu$ is the elasticity of supply) and the demand function for energy is of the modified isoelastic form ${ }^{9}$

$$
D_{E}(P)=(P+\delta)^{-\varepsilon} \text { where } \delta \geq 0 \text { and } \varepsilon>0
$$

The choke price $\bar{P}$ is the solution of the equation

$$
(\bar{P}+\delta)^{-\varepsilon}-\beta(z \bar{P})^{\mu}=0
$$

Then an increase in biofuel subsidy will lower the choke price for fossil fuels,

$$
\frac{d \bar{P}}{d z}=-\frac{\beta \mu z^{\mu-1}(\bar{P})^{\mu}}{\varepsilon(\bar{P}+\delta)^{-\varepsilon-1}+\mu \beta z^{\mu}(\bar{P})^{\mu-1}}<0 .
$$

From equation (11), we know that a Green Paradox outcome occurs if and only if $\int_{0}^{T}\left[D_{P} \frac{\partial P_{t}}{\partial z}+D_{z}\right] d t>$ 0. Recalling equation (9), we obtain the indirect effect

$$
D_{P} \frac{\partial P_{t}}{\partial z}=e^{r(t-T)}\left\{\frac{\beta \mu z^{\mu-1}(\bar{P})^{\mu}\left[\varepsilon\left(P_{t}+\delta\right)^{-\varepsilon-1}+\mu \beta z^{\mu}\left(P_{t}\right)^{\mu-1}\right]}{\varepsilon(\bar{P}+\delta)^{-\varepsilon-1}+\mu \beta z^{\mu}(\bar{P})^{\mu-1}}\right\}>0
$$

\footnotetext{
${ }^{9}$ A possible interpretation of the energy demand function (17) is that it is a derived demand function. For example, suppose a manufactured good is produced under constant returns to scale using two inputs, energy and labor, in fixed proportions, normalized at unity. Then the price of a unit of the manufatured good is $P+\delta$ where $P$ is the price of energy and $\delta$ is the wage rate. Under this interpretation, $\varepsilon$ is the price elasticity of demand for the manufactured good.
} 
Proposition 2: Under the demand and supply specification (16) and (17), a Green Paradox occurs if and only if parameter values are such that the cumulative indirect effect dominates the cumulative direct effect, i.e.,

$$
\int_{0}^{T}\left\{e^{r(t-T)}\left[\frac{\varepsilon\left(P_{t}+\delta\right)^{-\varepsilon-1}+\mu \beta z^{\mu}\left(P_{t}\right)^{\mu-1}}{\varepsilon(\bar{P}+\delta)^{-\varepsilon-1}+\mu \beta z^{\mu}(\bar{P})^{\mu-1}}\right]-\left(\frac{P_{t}}{\bar{P}}\right)^{\mu}\right\} d t>0
$$

where $P_{t}$ is given by (9) and $\bar{P}$ is given by (18). This condition is satisfied under plausible specifications of parameter values.

Proof: Using Lemma 1 and our specification of demand and supply as in (16) and (17), condition (13) is satisfied if and only if

$$
\int_{0}^{T}\left\{e^{r(t-T)}\left[\frac{\beta \mu z^{\mu-1}(\bar{P})^{\mu}\left(\varepsilon\left(P_{t}+\delta\right)^{-\varepsilon-1}+\mu \beta z^{\mu}\left(P_{t}\right)^{\mu-1}\right)}{\varepsilon(\bar{P}+\delta)^{-\varepsilon-1}+\mu \beta z^{\mu}(\bar{P})^{\mu-1}}\right]-\beta \mu z^{\mu-1}\left(P_{t}\right)^{\mu}\right\} d t>0
$$

This condition is equivalent to (19).

\section{Numerical examples}

While it is not possible to determine the sign of (19) analytically, we can compute it when parameter values are specified. First, $\bar{P}(z)$ is computed. Then $P_{t}$ is computed from (9). Next, we integrate (19) numerically. Finally, we compute (11).

In our base-line scenario, the parameters are:

$$
\varepsilon=\delta=\beta=\mu=1, \quad r=0.05, \quad c=0
$$

This means that the elasticity of supply of biofuel is unity, and the (residual) demand for fossil fuels is strictly convex, with the price elasticity of demand ranging from infinity (at the choke price $\bar{P}$ ) to zero (when the price approaches zero). Let the reserve size $R_{0}$ be large enough so that under this base-line scenario, the exhaustion time is $T=100$ years. Then we find that, starting at the initial subsidy factor $z=1$, an increase in $z$ leads to an earlier exhaustion time: $d T / d z=-2.09$. This result is in sharp contrast to the case where the residual demand is linear, where under zero extraction cost an increase in $z$ will cause a fall in the intial price $P_{0}$ just sufficiently to keep the quantity demanded $q_{0}$ (on the rotated demand curve) unchanged. With a strictly convex demand function, the initial price falls 
more sharply, increasing the quantity demanded $q_{0}$. Figure 3 shows the Green Paradox in this case.

\section{PLEASE PLACE FIGURE 3 HERE.}

The above computation shows that, given our specification (20), the Weak Green Paradox holds if the reserve size is such that $T=100$. Is this result sensitive to the size of the reserve? Let us vary the reserve size so that $T$ varies from 50 years to 200 years. We find that $d T / d z$ remains negative, and not far different from -2.09 . Table 1 below reports the value $d T / d z$ for various reserve sizes (and hence various $T$ ).

We also consider different initial subsidy levels keeping $\varepsilon=\delta=\beta=\mu=1, r=0.05$, $c=0, T=100$. Table 2 reports the results and shows there is a Green Paradox for this set of parameter values, for a wide range of values of the initial subsidy factor. Next, keeping $\beta=\delta=\mu=1, r=0.05, c=0, T=100$, we consider different values for $\varepsilon$, the price elasticity of demand for the manufactured good. The results are reported in Table 3. Again, for a wide range of possible values of this elasticity, the Green Paradox holds. We find that the greater is the elasticity $\varepsilon$, the stronger is the effect of an increase in the subsidy on the lowering of the exhaustion time. Finally, consider different values for supply elasticity of biofuels, $\mu$. We find that the Green Paradox holds for a wide range of $\mu$, as reported in Table 4. As shown in this Table 4, with the exception of the first column where the supply elasticity of biofuels is small, an increase in the subsidy rate will hasten the exhaustion of fossil fuels.

The intuition behind the sensitivity to the supply elasticity $\mu$ can be explained by noting that when the price elasticity of supply of biofuels is high ( $\mu$ large) the rising price along the Hotelling path induces very strong biofuel supply expansion. Hence, the demand for oil primarily decreases in the future rather than earlier. Consequently, oil owners have to sell more sooner and it is this outcome that works in favor of the Green Paradox. 


\section{The case of stock-dependent marginal extraction cost}

We now turn to an investigation of the possibility of a Green Paradox outcome in the case where extraction costs are stock-dependent, as specified in (1) with $C_{R}<0$, meaning that the extraction cost rises as the remaining stock falls. There are two possible scenarios. In the first scenario, the marginal cost of extracting the 'last drop of oil', although high, is still below the choke price for fossil fuels, and therefore all the fossil fuel stock will eventually be exhausted. In the second scenario, the last drop of oil is prohibitively expensive to extract, and therefore firms will abandon their deposits without exhausting them. ${ }^{10}$ We investigate the possibility of the Green Paradox in both cases.

It will be convenient to work with an explicit form of the function $C(q, R)$. Following Karp (1984), we postulate that $C\left(q_{t}, R_{t}\right)=\left[c_{0}+c_{1}\left(R_{0}-R_{t}\right)\right] q_{t}$, where $c_{0} \geq 0, c_{1} \geq 0$, and $R_{0}-R_{t} \geq 0$. Then $c_{0}+\left(R_{0}-R_{t}\right) c_{1}$ is the marginal cost of extraction at time $t$. At time $t=0$, the marginal extraction cost is at its lowest value, $c_{0}$. As extraction proceeds, the remaining stock $R_{t}$ falls, and the marginal extraction cost rises. As $R_{t}$ falls to 0 , the marginal extraction cost rises to $c_{0}+c_{1} R_{0}$. We call $c_{0}+c_{1} R_{0}$ the marginal cost of extracting the last drop of oil. The parameter $c_{1}$ represents the sensitivity of marginal cost to the remaining stock.

Under this specification, equation (8) reduces to $\dot{P}=r\left(P-\left(c_{0}+c_{1}\left(R_{0}-R\right)\right)\right.$.

As before, the demand for fossil fuels falls to zero at the "fossil fuel choke price" $\bar{P}$ defined by $D_{E}(\bar{P})-S(z \bar{P})=0$. Since the representative oil firm's marginal cost is $c_{0}+c_{1}\left(R_{0}-R_{t}\right)$, it is clear that: ${ }^{11}$

(i) if the marginal extraction cost of the last drop of oil is low, such that $c_{0}+c_{1} R_{0} \leq \bar{P}(z)$, then the representative firm will eventually exhaust all its stock,

(ii) if the marginal extraction cost of the last drop of oil is high, such that $c_{0}+c_{1} R_{0}>\bar{P}(z)$, the representative firm will abandon its deposit when the reserve level falls to some positive

\footnotetext{
${ }^{10}$ Some authors have therefore modeled the "resource exhaustion" in the sense of an "economic abandonment" of the deposit after the profitable part has been exploited (see for example Karp, 1984).

${ }^{11}$ See Karp (1984).
} 
level $R_{L}$ defined by

$$
c_{0}-c_{1}\left(R_{0}-R_{L}\right)=\bar{P}(z), R_{L}>0
$$

Let us consider the case where the marginal extraction cost of the last drop of oil is low, such that $c_{0}+c_{1} R_{0} \leq \bar{P}(z)$. Then the equilibrium paths of price and quantity are obtained from solving the following system of equations: $\dot{P}=r\left(P-\left(c_{0}+c_{1}\left(R_{0}-R\right)\right)\right.$ and $\dot{R}=-D(P ; z)$, subject to the boundary conditions $R(0)=R_{0}, P_{T}=\bar{P}(z)$ and $R_{T}=0$.

\section{The case of linear demand for fossil fuels}

In this case, we can show that the Green Paradox does not hold. This is stated as Proposition 3.

Proposition 3: If the fossil fuel demand function $D(P ; z)$ is linear in $P$, and the entire stock $R_{0}$ is exhausted at some time $T$, then

(i) an increase in the subsidy factor z will delay the exhaustion date,

(ii) higher sensitivity of extraction cost with respect to the remaining stock results in a later exhaustion date.

Proof: See the Appendix.

As a numerical example, let $a=3, b=\beta=z=1$ and $\bar{R}=80$. We find that the stock $\bar{R}$ will be exhausted in 370 years. If the subsidy factor is $z=1.1$, we find that $T$ increases to 410 years.

\section{The case of non-linear demand}

We consider the more general case of non-linear demand and suppose that $D(P, z)=$ $(P+\delta)^{-\varepsilon}-\beta(z P)^{\mu}$. Then $\bar{P}(z)$ is the solution of $(P+\delta)^{-\varepsilon}-\beta(z P)^{\mu}=0$. The system to be analyzed is: $\dot{P}_{t}=r\left[P_{t}-\left(c_{0}+c_{1}\left(R_{0}-R_{t}\right)\right]\right.$ and $\dot{R}_{t}=-(P+\delta)^{-\varepsilon}+\beta(z P)^{\mu}$, subject to three boundary conditions: $R_{0}$ given, $R_{T}=0, P_{T}=\bar{P}(z)$. Unlike linear demand case, we cannot obtain an analytical solution.

Consider an example. Let $\varepsilon=\mu=\beta=\delta=1$. Then $\bar{P}$ is the solution of $(P+1)^{-1}-z P=$ 0. At $z=1$, the fossil fuel choke price is 0.618. Assuming that $c_{0}=0.005, c_{1}=0.0001$ and $\bar{R}=80$, we can solve for the current oil price $P(0)=0.017$, and the exhaustion date 
$T \simeq 106.9$ years. These cost and oil reserve parameters imply that the current extraction cost/price ratio is $29 \%$. Until the exhaustion date, costs in this case increases slightly from 0.005 to 0.013 , but the fuel price increases faster from 0.017 to 0.618 , and thus the relevant cost/price ratio at the exhaustion date is just $2 \% .{ }^{12}$

Does a small increase in $z$ lead to an increase or a decrease in $T$ ? The answer depends on various parameters, particularly cost sensitivity or $c_{1}$. Our numerical simulations show that if extraction costs increase faster as the reserve depletes (a large value of $c_{1}$ ), then, starting from $z=1$, a small increase in the subsidy will make oil reserves last longer (a larger $T$ ). On the other hand, if $c_{1}$ is small enough, then an increase in the subsidy may lead to earlier exhaustion. We illustrate this in Table 5 where the subsidy $z$ is increased from 1 to 1.2 $(\Delta z=0.2)$. Table 5 illustrates it is possible to find a large range of cases where fossil fuel reserves are exhausted faster, and the Green Paradox holds.

The findings in Table 5, however, do not imply the Green Paradox is a general result. Indeed, if condition (21) holds, we can show that with linear demand and a marginal extraction costs that increases linearly with accumulated extraction, and without technological change, fossil fuel deposits are abandoned before exhaustion and a subsidy for biofuels production results in a smaller overall consumption of fossil fuels. In that case, we say that the Green Paradox does not hold in the long run. However, the long run is very far away (in fact, abandonment takes place at time infinity). Thus, even when the Green Paradox does not hold even in the long run, our results indicate that it can plausibly hold in the short or medium term.

We emphasize that the time period over which the Green Paradox holds is critically important. In terms of climate change and avoiding the severe impacts of climate change, what happens to cumulative emissions over the next 30 years interval is critical. It is this

\footnotetext{
${ }^{12}$ For fossil fuel producers to abandon extraction before reserves are exhausted, the subsidy must satisfy:

$$
c_{0}+c_{1} R_{0}=0.013>\bar{P}(z) \text { or } z>153.8 .
$$
}


period of time that is likely to be the important period in terms of biofuels subsidies as we might reasonably assume that new, carbon neutral energy technologies will become more widespread beyond 30 years. Thus, in the time periods that matter we have real cause for concern that biofuel subsidies may actually encourage larger GHG emissions from fossil fuel combustion and increase the likelihood of the more severe impacts of climate change. ${ }^{13}$

Another relevant issue is technological change that affects extraction costs and the net price path on non-renewables. Technological change would seem to be especially important in terms of stock-dependent extraction costs. Positive technological change should offset the effect of stock-dependent extraction, and may do so for a long time. The overall impact of technological change would depend on the relative changes of $z$ over time, on the extent to which technological changes affect the extraction costs and the cost of biofuel production, and the nature of stock dependent costs.

\section{Extensions}

In this section, we outline two extensions of our model. The first extension concerns the possibility of Green Paradox when the fossil fuels are supplied by a cartel, while biofuel producers are perfectly competitive. The second extension deals with carbon leakage in a two-country world where only one country subsidizes biofuel production.

\section{Cartel extraction}

Assume that the exhaustible resource cartel takes the biofuel subsidy factor $z$ as a given constant. How does an increase in $z$ affect the extraction path? As before, the residual demand function facing the oil producer is $D(P ; z) \equiv D_{E}(P)-S(z P)$. The choke price for fossil fuels is $\bar{P}$, where $D_{E}(\bar{P})-S_{B}(z \bar{P})=0$, and $\bar{P}$ is decreasing in $z$. For simplicity we only consider the case of constant marginal cost of extraction, $c$. We assume that the cartel's extraction matches the demand for fossil fuels, $q_{t}=D\left(P_{t} ; z\right)$. Its optimization problem

\footnotetext{
${ }^{13}$ If one takes into account the possible feedback effect (such as additional emissions from the permafrost biomass that could result from increased GHGs concentrations in the medium run) the steeper path of cumulative fossil fuel extraction in the medium run can result in greater irreversible damages even if long run total extraction is lower due to abandonment of reserves. See Winter (2011) on this point.
} 
consists of choosing a time path of price $P_{t} \in[0, \bar{P}]$ and a terminal date $T$ to maximize the present value of its stream of discounted profit:

$$
\max _{T, P_{t}} \int_{0}^{T} e^{-r t}\left[\left(P_{t}-c\right) D\left(P_{t} ; z\right)\right] d t
$$

subject to the constraint $\dot{R}_{t}=-D\left(P_{t} ; z\right)$, where $R_{T} \geq 0, R_{0}$ given.

In this case, we obtain the following results.

Proposition 4: Assume that the demand function for fuel and the supply function of biofuel are both linear. Then, under monopoly extraction,

(i) if extraction costs are zero $(c=0)$, an increase in the biofuel subsidy factor $z$ will have no effect on the date of exhaustion of the resource stock $R_{0}$;

(ii) if extraction costs are positive $(c>0)$, an increase in the biofuel subsidy factor $z$ will delay the date of exhaustion of the resource stock $R_{0}$.

Proposition 5: Under non-linear demand, a Green Paradox can arise when fossil fuels are supplied by a cartel.

\section{Carbon leakages in a two country-model}

An important policy issue is whether well-meaning environmental policies of advanced industrialized countries is likely to lead to a Green Paradox because emerging market economies are not willing to reduce their GHG emissions. Earlier works on this important topics include Bohm (1993) and Hoel (1994). Recent discussions of carbon leakage in the context of trade can be found in Copeland and Taylor (2005) and Ishikawa and Kiyono (2006). However, these authors did not address the relationship between non-optimal biofuel policies and carbon leakage effects in a dynamic setting, a connection which we now take up. Let us consider the case where there are two countries with different energy policies. For simplicity we do not consider game theoretic or food policy issues (Bandyopadhyay et al. 2009). Let us say the "home country" is the U.S. and the "foreign country" is China. There is no biofuel production in China. Assume that U.S. biofuels are not exported to China (e.g. because of high transport costs or other barriers to trade, or because the U.S. production subsidies are 
only given to domestically earmarked consumption).

Let $P_{t}$ be the world price of fossil fuels. Assume that China's inverse demand function for fuels is $P_{t}=A-E_{t}^{c} / M^{c}$ where $E_{t}^{c}$ is the quantity demanded in China, i.e., China's demand for energy is $D_{E}^{c}\left(P_{t}\right)=M^{c}\left(A-P_{t}\right)$. Similarly, the US inverse demand function for fuels is $P_{t}=A-E_{t}^{u} / M^{u}$. The ratio $M^{c} / M^{u}$ is a measure of China's market size relative to the U.S.'s market size. By an appropriate choice of units, we set $M^{u}=1$ in what follows.

When the price is $P_{t}$, U.S. biofuel producers earn $z P_{t}$ for each unit they sell domestically, where $z$ is the subsidy factor. The biofuel supply function is $S_{B}=\beta(z P)^{\mu}$ and the U.S.'s residual demand for fossil fuels is $D^{u}(P ; z)=D_{E}^{u}\left(P_{t}\right)-\beta(z P)^{\mu}=A-P-\beta(z P)^{\mu}$. Let $\bar{P}_{u}$ be the solution of $A-\bar{P}_{u}-\beta\left(z \bar{P}_{u}\right)^{\mu}=0$.

Given a positive constant subsidy factor $z>0$, the world equilibrium consists of two phases. In the first phase, fossil fuels are consumed in both the U.S. and China. This phase ends at an endogenously determined time $T^{u}$, when $P_{t}$ reaches the value $\bar{P}_{u}$. In the second phase, fossil fuels are only used in China, and U.S. energy demand is completely satisfied by biofuel production. ${ }^{14}$ The second phase ends at time $T^{w}$, when the world price of fossil fuels reaches the choke price $A$ and China's demand for fossil fuels becomes zero.

Our task is to find out how the subsidy rate $z$ influences the two critical times $T^{u}$ and $T^{w}$, and how it influences the equilibrium price path of fossil fuels, and hence the rate of emissions of $\mathrm{CO}_{2}$ at each point of time.

Let $D^{w}(t)$ be the world (US and China) demand for fossil fuels during phase I, i.e. $D^{w}(t)=D^{u}\left(P_{t} ; z\right)+D_{E}^{c}\left(P_{t}\right)$, for $t<T^{u}$. For $t \geq T^{u}$, let $D_{E}^{c}(t)$ be China's demand for fossil fuels in phase II. Let $R_{0}$ be the initial stock of fossil fuels. Equilibrium requires that the total use of fossil fuels equals its stock:

$$
\int_{0}^{T^{u}} D^{w}(t) d t+\int_{T^{u}}^{T^{w}} D_{E}^{c}(t) d t=R_{0}
$$

We can prove the following Proposition.

\footnotetext{
${ }^{14}$ In this section, we use the word biofuels to represent all other renewable energy sources.
} 
Proposition 6: An increase in the subsidy factor $z$ will lengthen Phase II and may shorten Phase I. The exhaustion date will be brought closer to the present if the U.S.'s choke price is highly responsive to increases in biofuel subsidies.

\section{Concluding Remarks}

We examine several possible cases under which a Green Paradox may arise from a policy of biofuel subsidies whereby the supply-side response by fossil fuel producers more than offsets any gains from direct substitution to biofuels. Whether the Green Paradox holds or not depends on demand and supply elasticities, expected changes in subsidies, technological change in fossil fuel extraction and how extraction costs respond to changes in remaining reserves. We find that a Green Paradox is not a general result, but under plausible assumptions it may exist.

A key implication of our theoretical work is the need to test empirically whether a Green Paradox exists. Equally as important, our work shows the importance of considering: (1) the inter-temporal effects of biofuel subsidies on fossil fuel production; (2) the trade effects of biofuel subsidies even for countries that neither produce nor consume biofuels; and (3) the industry structure (competitive or cartel) of fossil fuel production.

The implications of our findings on energy policy are several. First, and foremost, is the importance and necessity of analyzing the impacts of biofuels policies in a dynamic context. Second, domestic policies of large biofuel producing nations must be evaluated in a welfare context that includes the effects on both biofuel and fossil fuel consumption globally. Third, we provide an additional reason why biofuel subsidies are a sub-optimal policy and, in some cases, may even generate perverse outcomes that are contrary to the stated objectives which supposedly justify their use.

Further development of our dynamic models is necessary to take into account gametheoretic issues, the effects of technological change on extraction costs, the impacts of GHG atmospheric concentrations and the rates of decay, and the direct GHG reductions from 
biofuel-fossil fuel substitution at a given price. Nevertheless, our findings are sufficiently well developed to require, at the very least, that policy makers carefully evaluate the dynamic and supply-side effects of biofuel subsidies on the extraction rate of fossil fuels.

Acknowledgement An early version of this paper was presented at the SURED conference (Ascona, 2010). The final version was completed at Ifo Institute in 2011. In their research on the Green Paradox, the authors have benefited from helpful discussions with Reyer Gerlagh, Michael Hoel, Chuck Mason, Karen Pittel, Rick van der Ploeg, Hans-Werner Sinn, Sjak Smulders, and Cees Withagen.

\section{References}

[1] Allen, Myles R., D. J. Frame, C. Huntingford, C.D. Jones, J. A. Lowe, M. Meinhausen and N. Meinhausen (2009), "Warming caused by cumulative carbon emissions towards the trillionth tonne," Nature, Volume 458(7242), pp. 1163-1166, 30 April 2009, doi:10.1038/nature08019.

[2] Bahel, E., G. Gaudet and W. Marrouch (2011), "The Economics of Oil, Biofuel and Food Commodities", CIREQ working paper, Université de Montréal.

[3] Bandyopadhyay, S., S. Bhaumik and H.J. Wall (2009), "Biofuel Subsidies: An OpenEconomy Analysis". Discussion Paper No. 4584, The Institute for the Study of Labor (IZA).

[4] Berg, E., S. Kverndokk, and K. E. Rosendahl (2002), "Oil Exploration under Climate Treaties," Journal of Environmental Economics and Management, 44(3), 493-516.

[5] Bohm, P. (1993), "Incomplete International Cooperation to Reduce $\mathrm{CO}_{2}$ emissions: Alternative Policies," Journal of Environmental Economics and Management 24: 25871. 
[6] Chakravorty, U., M.-H. Hubert, and L. Nostbakken (2009), "Fuel versus Food," Annual Review of Resource Economics, 1: 645-663.

[7] Chakravorty, U., M.-H. Hubert, M. Moreaux, and L. Nostbakken (2011), Will Biofuel Mandates Raise Food Prices? Working Paper 2011-1, University of Alberta.

[8] Copeland, B. and M. S. Taylor, (2005), "Free Trade and Global Warming: A Trade Theory View of the Kyoto Protocol," Journal of Environmental Economics and Management 49: 205-234.

[9] Dasgupta, P. S. and G.M. Heal (1979), Economic Theory and Exhaustible Resources. Cambridge Economic Handbooks, Cambridge University Press.

[10] de Gorter, H. and D.R. Just 2010, "The Social Costs and Benefits of Biofuels: The Intersection of Environmental, Energy and Agricultural Policy," Applied Economics Perspectives and Policy, 32(1): 4-32.

[11] Di Maria, C., S. Smulders, and E. van der Werf (2008), " Absolute Abundance and Relative Scarcity: Announced Policy, Resource Extraction, and Carbon Emissions," FEEM Working Papers, 92.2008.

[12] Eichner, T. and R. Pethig (2010), "Carbon Leakage, the Green Paradox and Perfect Future Markets," CESifo Working Paper No. 2546.

[13] Farzin, Y. H. (1992), "The time path of scarcity rent in the theory of exhaustible resources," Economic Journal 102, 813-830.

[14] Fischer, C. and S. Salant (2012), Alternative Climate Policies and Intertemporal Emissions Leakages, RFF Discussion Paper DP 12-16, Resources for the Future, Washington, D.C. 
[15] Food and Agriculture Organization of the United Nations (2008), "High-level Conference on World Food Security: The Challenges of Climate Change and Bioenergy", Rome, 3-5 June.

[16] Gaudet, G. (2007), "Natural Resource Economics under the Rule of Hotelling," Canadian Journal of Economics 40(4): 1033-1-59.

[17] Gerlagh , Reyer and M. Liski (2008), "Strategic Oil Dependence," FEEM Working Paper 72.2008.

[18] Gerlagh, Reyer (2011), "Too Much Oil," CESifo Economic Studies, 57(10),79-102.

[19] Heal, G. M. (1976), "The Relationship between Price and Extraction Cost for a Resource with a Backstop Technology," The Bell Journal of Economics, 7(2): 371-378.

[20] Heal, G.M. (1985), “ Interaction between Economy and Climate: A Framework for Policy Design under Uncertainty," in V. Smith and A. White (eds.), Advances in Applied Microeconomics, JAI Press, pp. 151-168.

[21] Hill, J., E. Nelson, D. Tilman, S. Polasky and D. Tiffany (2006), "Environmental, economic, and energic costs and benefits of biodiesel and ethanol biofuels", Proceedings of the National Academy of Sciences 103 (30): 11206-11210.

[22] Hoel, M. (1978), "Resource Extraction, Substitute Production, and Monopoly," Journal of Economic Theory 19, 28-77.

[23] Hoel, M. (1983), "Monopoly Resource Extractions under the Presence of Predetermined Substitute Production," Journal of Economic Theory 30, 201-212.

[24] Hoel, M. (1994), "Efficient Climate Policy in the Presence of Free Riders," Journal of Environmental Economics and Management 27(3): 259-274.

[25] Hoel, M. (2008), "Bush Meets Hotelling: Effects of Improved Renewable Energy Technology on Greenhouse Gas Emissions", CESifo Working Paper No. 2492. 
[26] Hoel, M. (2010), "Climate Change and Carbon Tax Expectations," CESifo Working Paper no. 2966.

[27] Hoel, M. (2011), "The Green Paradox and Greenhouse Gas Reducing Investment", International Review of Environmental and Resource Economics (www.irere.net), forthcoming.

[28] Hoel, M. and S. Kverndokk, (1996), "Depletion of Fossil Fuels and the Impacts of Global Warming," Resource and Energy Economics, 18(2), 115-136.

[29] Ishikawa, J. and K. Kiyono (2006), "Greenhouse-gas Emission Controls in an Open Economy," International Economic Review, 47(2): 431-50.

[30] Karp, L. S. (1984), "Optimality and Consistency in a Differential Game with NonRenewable Resources," Journal of Economic Dynamics and Control 8: 73-97.

[31] Koplow, D., (2007). 'Biofuel - At what cost? Government support for ethanol and biodiesel in the United States: 2007 update', Prepared for the Global Subsidies Initiative (GSI) of the International Institute for Sustainable Development, Geneva, Switzerland. http://www.globalsubsidies.org/files/assets/Brochure_-_US_Update.pdf

[32] Lapan, H. and G. Moschini (2009), "Biofuels Policies and Welfare: Is the Stick of Mandates Better than the Carrot of Subsidies?, "Iowa State University Department of Economics Working Paper No. 09010 Ames, Iowa.

[33] Long, N. V. and H.-W. Sinn (1985), "Surprise Price Shift, Tax Changes and the Supply Behaviour of Resource Extracting Firms", Australian Economic Papers, 24(45): 278289.

[34] Moschini, G., H. Lapan, J. Cui and J. Cooper (2010), "Assessing the Welfare Effects of US Biofuel Policies," AgBioForum, 13(4): 370-374. 
[35] Pearce, D.W. and R.K. Turner (1990), Economics and Natural Resources and the Environment, Harvester Wheatsheaf.

[36] Ploeg, F. van der, and C. Withagen (2010), "Is There Really a Green Paradox?" Oxcarre Research Paper 35, University of Oxford, Oxford, U.K.

[37] Rubio, S. and L. Escriche (2001), "Strategic Pigouvian Taxation, Stock Externalities and Polluting Non-renewable Resources," Journal of Public Economics 79: 297-313.

[38] Salo, S. and O. Tavohnen (2001), "Oligopoly Equilibria in Non-renewable Resource Markets," Journal of Economic Dynamics and Control 25: 671-702.

[39] Sinclair, P.J.N. (1992), "High Does Nothing and Rising is Worse: Carbon Taxes Should Keep Falling to Cut Harmful Emissions", Manchester School 60: 41-52.

[40] Sinclair, P.J.N. (1994), "On the Optimal Trend of Fossil Fuel Taxation," Oxford Economic Papers 46: 869-877

[41] Sinn, H.-W. (2008a), "Public Policies Against Global Warming: A Supply-Side Approach", International Tax and Public Finance, 15(4):360-394.

[42] Sinn, H.-W. (2008b), Das Grüne Paradoxon: Plädoyer für eine illusionsfreie Klimatpolitik, Econ Verlag, Berlin.

[43] Sinn, H.-W. (2012), The Green Paradox; A Supply-Side Approach to Global Warming, MIT Press, Cambrigde, MA.

[44] Steenblik, R. (2007), "Biofuels - At What Cost? Government support for ethanol and biodiesel in selected OECD countris", Global Subsidies Initiative, Geneva.

[45] Strand, J. (2007), "Technology Treaties and Fossil Fuels Extraction," The Energy Journal 28: 129-142. 
[46] Tahvonen, O. (1997), "Fossil Fuels, Stock Externalities, and Backstop Technology," Canadian Journal of Economics, 30(4), 855-874.

[47] Ulph, A. and D. Ulph (1994), "The Optimal Time Path of a Carbon Tax", Oxford Economic Papers 46: 857-868.

[48] UNEP, (2009), "Towards Sustainable Production and Use of Resources: Assessing Biofuels"

[49] Winter, R. A. (2011), "Innovations and the Dynamics of Global Warming," Working Paper, Sauder School of Business, University of British Columbia.

\section{APPENDIX}

\section{Proof of Proposition 3}

With the linear demand $D\left(P_{t} ; z\right)=a-(b+\beta z) P_{t}$, the fossil fuel choke price is $\bar{P}(z)=\frac{a}{b+\beta z}$. Define $Y_{t}=R_{0}-R_{t}$. Assume that the marginal cost of extracting the last drop of oil is lower than the fossil fuel choke price:

$$
R_{0}<\frac{a}{c_{1}(b+\beta z)}-\frac{c_{0}}{c_{1}}
$$

Consider the system

$$
\begin{gathered}
\dot{P}_{t}=r\left[P_{t}-\left(c_{0}+c_{1} Y_{t}\right)\right], \quad r>0, c_{0}>0, c_{1}>0 \\
\dot{Y}_{t}=D\left(P_{t} ; z\right)=a-(b+\beta z) P_{t}, \quad a>0, b>0, \beta>0, z>0
\end{gathered}
$$

subject to three boundary conditions: $Y_{0}=0, Y_{T}=R_{0}, P_{T}=\bar{P}(z)$.

Write the system of differential equations in matrix form:

$$
\left[\begin{array}{l}
\dot{P} \\
\dot{Y}
\end{array}\right]=\left[\begin{array}{ll}
a_{11} & a_{12} \\
a_{21} & a_{22}
\end{array}\right]\left[\begin{array}{l}
P \\
Y
\end{array}\right]+\left[\begin{array}{l}
b_{1} \\
b_{2}
\end{array}\right]
$$


where $a_{11}=r, a_{12}=-r c_{1}, a_{21}=-(b+\beta z), a_{22}=0, b_{1}=-r c_{0}$ and $b_{2}=a$.Let $\rho_{1}<0$ and $\rho_{2}>0$ be the characteristic roots. Let $(\widetilde{P}, \widetilde{Y})$ denote the stationary point. Then the general solution is

$$
\left[\begin{array}{c}
P(t)-\widetilde{P} \\
Y(t)-\tilde{Y}
\end{array}\right]=\left[\begin{array}{c}
h_{1} \\
-\left(a_{12}\right)^{-1}\left(a_{11}-\rho_{1}\right) h_{1}
\end{array}\right] \exp \left(\rho_{1} t\right)+\left[\begin{array}{c}
h_{2} \\
-\left(a_{12}\right)^{-1}\left(a_{11}-\rho_{2}\right) h_{2}
\end{array}\right] \exp \left(\rho_{2} t\right)
$$

where $h_{1}$ and $h_{2}$ are constants (to be determined using boundary conditions).

Using the boundary conditions $P_{T}-\widetilde{P}=0$ and $Y_{T}=R_{0}$, we can solve for $h_{1}$ and $h_{2}$ and finally we solve for the exhaustion time $T$ as follows:

$$
\frac{\left(\rho_{2}-\rho_{1}\right) \exp \left(\rho_{2} T\right)}{-\rho_{1}+\rho_{2} \exp \left[\left(\rho_{2}-\rho_{1}\right) T\right]}=\frac{\widetilde{Y}-R_{0}}{\widetilde{Y}}
$$

This equation has a unique solution $T>0$ (which depends on $z$ ). Define

$$
F(T, z)=\frac{\left(\rho_{2}-\rho_{1}\right)}{\rho_{2} e^{-\rho_{1} T}-\rho_{1} e^{-\rho_{2} T}}
$$

and

$$
G(T, z) \equiv F(T, z)-\left(\frac{\widetilde{Y}(z)-\bar{R}}{\widetilde{Y}(z)}\right)
$$

To prove part (i), note that the effect on $T$ of an increase in the subsidy $z$ is

$$
\frac{d T}{d z}=-\frac{\frac{\partial G}{\partial z}}{\frac{\partial G}{\partial T}}
$$

We can show that

$$
\frac{\partial G}{\partial T}=-\frac{\rho_{1} \rho_{2}\left(\rho_{2}-\rho_{1}\right)^{2} e^{\rho_{2} T}}{\left\{\rho_{2} e^{\left(\rho_{2}-\rho_{1) T}\right.}-\rho_{1}\right\}^{2}}\left[e^{\rho_{2} T}-e^{\left(2 \rho_{2}-\rho_{1}\right)}\right]<0
$$

and

$$
\frac{\partial G}{\partial z}=\frac{\partial F}{\partial z}-\bar{R}[\widetilde{Y}(z)]^{-2} \frac{d \widetilde{Y}}{d z}>0
$$

since $\frac{\partial F}{\partial z}>0$.

To prove part (ii), we use $\frac{d T}{d c_{1}}=-\left(\frac{\partial G}{\partial c_{1}}\right) /\left(\frac{\partial G}{\partial T}\right)$ and show that $\left(\frac{\partial G}{\partial c_{1}}\right)>0$.

\section{Proof of Proposition 4}


Denote the elasticity of the demand for fossil fuels by $\theta_{t}\left(P_{t} ; z\right)$, defined by

$$
\theta_{t}\left(P_{t} ; z\right) \equiv-\frac{P_{t}}{D}\left(\frac{\partial D}{\partial P_{t}}\right)>0
$$

where we assume

$$
\frac{\partial \theta_{t}\left(P_{t} ; z\right)}{\partial P_{t}} \geq 0
$$

Let $\psi_{t}$ denote the current-value shadow price of the stock $R_{t}$ and let $H_{t}$ denote the current-value Hamiltonian. Then

$$
H_{t}=\left(P_{t}-c\right) D\left(P_{t} ; z\right)-\psi_{t} D\left(P_{t} ; z\right)
$$

The optimality conditions for the monopolist are

$$
\begin{gathered}
P_{t}\left[1-\frac{1}{\theta_{t}}\right]-c-\psi_{t}=0 \Leftrightarrow \frac{\partial H_{t}}{\partial P_{t}}=0 \\
\dot{\psi}_{t}=r \psi_{t} \\
\psi_{T} \geq 0, \quad R_{T} \geq 0, \quad \psi_{T} R_{T}=0 \\
H_{T}=\left[P_{T}-c-\psi_{T}\right] D\left(P_{T} ; z\right)=0
\end{gathered}
$$

One can show that conditions imply that $\psi_{T}=P_{T}-c>0, R_{T}=0, P_{T}=\bar{P}, D\left(P_{T} ; z\right)=0$, and $\theta_{T}=\infty$. In particular, we obtain the Hotelling Rule for the monopolist: the present value of marginal profit is the same for all $t \in[0, T]$ :

$$
\left[\left(1-\frac{1}{\theta_{t}\left(P_{t} ; z\right)}\right) P_{t}-c\right]=(\bar{P}-c) e^{r(t-T)}
$$

Equation (23) implicitly defines the monopolist's optimal price $P_{t}^{m}$ as a function of $\bar{P}, z$, $t$ and $T$ :

$$
P_{t}^{m}=\phi^{m}(\bar{P}(z), t, T ; z)
$$

We make use of (24) to determine the monopolist's optimal exhaustion time $T$. It is the value of $T$ such that total accumulated extraction equals the initial reserve level $R_{0}$.

$$
\int_{0}^{T} D_{E}\left(\phi^{m}(\bar{P}(z), t, T ; z) ; z\right) d t=R_{0}
$$


The following result follows immediately:

Result 1 An increase in the subsidy factor $z$ will bring the monopolist's resourceexhaustion date $T$ closer to the present if and only if the indirect effect outweighs the direct effect, i.e.,

$$
\int_{0}^{T}\left[\frac{\partial D}{\partial P_{t}}\left(\frac{\partial P_{t}}{\partial z}\right)+\frac{\partial D}{\partial z}\right] d t>0
$$

where

$$
\frac{\partial P_{t}}{\partial z} \equiv \frac{\partial \phi^{m}}{\partial \bar{P}} \frac{d \bar{P}}{d z}+\frac{\partial \phi^{m}}{\partial z} .
$$

We now turn to the case of linear demand:

Let $D_{E}(P)=a-b P$ and $S=\beta z P-g$, where $a>0, b>0, \beta>0$ and $g \geq 0$. Then

$$
\phi^{m}(\bar{P}(z), t, T ; z)=\frac{1}{2}\left[(\bar{P}-c) e^{r(t-T)}+c+\frac{a}{b+z}\right]
$$

and

$$
D_{P}\left(\frac{\partial \phi^{m}}{\partial \bar{P}} \frac{d \bar{P}}{d z}+\frac{\partial \phi^{m}}{\partial z}\right)+D_{z}=-\frac{c}{2}\left(1-e^{-r(T-t)}\right) \leq 0
$$

Hence (i) if extraction costs are zero $(c=0)$, an increase in the biofuel subsidy factor $z$ will have no effect on the date of exhaustion of the resource stock $R_{0}$ and (ii) if extraction costs are positive $(c>0)$, an increase in the biofuel subsidy factor $z$ will delay the date of exhaustion of the resource stock $R_{0}$

Proof of Proposition 5: Assume the functional forms $S(z P)=\beta(z P)^{\mu}$ where $\beta>0$ and $\mu>0$ and $D_{E}(P)=(P+\delta)^{-\varepsilon}$ where $\delta \geq 0$ and $\varepsilon>0$. Let $\mu=1$. Then $D=$ $(P+\delta)^{-\varepsilon}-\beta z P$, and the elasticity of demand for fossil fuels is

$$
\theta_{t}=\frac{\left[\varepsilon\left(P_{t}+\delta\right)^{-\varepsilon-1}+\beta z\right] P_{t}}{\left(P_{t}+\delta\right)^{-\varepsilon}-\beta z P_{t}}>0 \text { for } P_{t}<\bar{P}
$$

Note that if $\beta z>0$ and $\varepsilon \geq 1$ then $\theta_{t}>1$ because

$$
\theta_{t}>\frac{\varepsilon P_{t}}{P_{t}+\delta} \geq \varepsilon
$$

Equation (23) becomes

$$
\left\{P_{t}-\frac{1}{\theta_{t}} P_{t}-c\right\}-(\bar{P}-c) e^{r(t-T)}=0
$$


Denote the right-hand side of equation (27) by $F\left(P_{t}, \bar{P}, t, T, z\right)$. Equation (27) yields the implicit function $P_{t}=\phi^{m}(\bar{P}(z), t, T ; z)$. Then

$$
\frac{\partial \phi^{m}}{\partial \bar{P}}=-\frac{\partial F / \partial \bar{P}}{\partial F / \partial P_{t}}=\frac{e^{r(t-T)}}{\left(1-\frac{1}{\theta_{t}}\right)-P_{t} \frac{d}{d P_{t}}\left(\frac{1}{\theta_{t}}\right)} \equiv \frac{e^{r(t-T)}}{\Omega_{t}}>0
$$

where $\Omega_{t}>0$. Furthermore,

$$
\frac{\partial \phi^{m}}{\partial z}=-\frac{\partial F / \partial z}{\partial F / \partial P_{t}}
$$

where

$$
\partial F / \partial z=-\frac{P_{t}}{\theta_{t}^{2}}\left(\frac{\partial \theta_{t}}{\partial z}\right)<0
$$

and

$$
\frac{\partial \theta_{t}}{\partial z}=\frac{\beta P_{t}}{(D)^{2}}\left[D+P_{t} \varepsilon(P+\delta)^{-\varepsilon-1}+z P_{t}\right]>0
$$

(a higher biofuel subsidy increases the elasticity of demand for fossil fuels at any given price). Consequently,

$$
\frac{\partial \phi^{m}}{\partial z}=-\frac{\frac{\beta P_{t}^{2}}{\left(\theta_{t} D\right)^{2}}\left[D+P_{t} \varepsilon(P+\delta)^{-\varepsilon-1}+z P_{t}\right]}{\Omega_{t}}<0
$$

We can now compute the crucial expression in Result 1:

$$
\begin{gathered}
\frac{\partial D_{f}}{\partial P_{t}}\left(\frac{\partial \phi^{m}}{\partial \bar{P}} \frac{d \bar{P}}{d z}+\frac{\partial \phi^{m}}{\partial z}\right)+\frac{\partial D}{\partial z} \\
=\frac{\varepsilon\left(P_{t}+\delta\right)^{-\varepsilon-1}+\beta z}{\Omega_{t}}\left(\frac{\bar{P} \beta e^{r(t-T)}}{\varepsilon(\bar{P}+\delta)^{-\varepsilon-1}+\beta z}+\frac{\beta P_{t}^{2}}{\left(\theta_{t} D\right)^{2}}\left[D+P_{t} \varepsilon(P+\delta)^{-\varepsilon-1}+z P_{t}\right]\right)-\beta P_{t}
\end{gathered}
$$

Using this expression, the integral (26) can be positive or negative, depending on parameter values

\section{Proof of Proposition 6}

When the price is $P_{t}$, U.S. biofuel producers earn $z P_{t}$ for each unit they sell domestically, where $z$ is the subsidy factor. The biofuel supply function is $S_{B}=\beta(z P)^{\mu}$ and the U.S.'s residual demand for fossil fuels is

$$
D^{u}(P ; z)=D_{E}^{u}\left(P_{t}\right)-\beta(z P)^{\mu}=A-P-\beta(z P)^{\mu} \text { since } M^{u}=1 .
$$


Let $\bar{P}_{u}$ be the solution of

$$
A-\bar{P}_{u}-\beta\left(z \bar{P}_{u}\right)^{\mu}=0
$$

Note that

$$
\frac{d \bar{P}_{u}}{d z}=-\frac{z^{\mu-1}\left(\bar{P}_{u}\right)^{\mu}}{\frac{1}{\beta \mu}+z^{\mu}\left(\bar{P}_{u}\right)^{\mu-1}}<0
$$

Given a positive constant subsidy factor $z>0$, the world equilibrium consists of two phases. In the first phase, fossil fuels are consumed in both the U.S. and China. This phase ends at an endogenously determined time $T^{u}$, when $P_{t}$ reaches the value $\bar{P}_{u}$. In the second phase, fossil fuels are only used in China, and U.S. energy demand is completely satisfied by biofuel production. The second phase ends at time $T^{w}$, when the world price of fossil fuels reaches the choke price $A$ and China's demand for fossil fuels becomes zero.

Our task is to find out how the subsidy rate $z$ influences the two critical times $T^{u}$ and $T^{w}$, and how it influences the equilibrium price path of fossil fuels, and hence the rate of emissions of $\mathrm{CO}_{2}$ at each point of time.

Let $D^{w}(t)$ be the world (US and China) demand for fossil fuels during phase I, i.e. $D^{w}(t)=D^{u}\left(P_{t} ; z\right)+D_{E}^{c}\left(P_{t}\right)$, for $t<T^{u}$. For $t \geq T^{u}$, let $D_{E}^{c}(t)$ be China's demand for fossil fuels in phase II. Let $R_{0}$ be the initial stock of fossil fuels. Equilibrium requires that the total use of fossil fuels equals its stock:

$$
\int_{0}^{T^{u}} D^{w}(t) d t+\int_{T^{u}}^{T^{w}} D_{E}^{c}(t) d t=R_{0}
$$

We begin by evaluating the second integral on the left-hand side of (30). Assume zero extraction cost and perfect competition. Hotelling's Rule gives us,

$$
P_{t} e^{-r t}=P\left(T_{u}\right) e^{-r T^{u}}=P\left(T^{w}\right) e^{-r T^{w}}
$$

Given that $P\left(T^{w}\right)=A$ and $P\left(T_{u}\right)=\bar{P}_{u}$,

$$
T^{w}-T^{u}=\frac{1}{r}\left(\ln A-\ln \bar{P}_{u}(z)\right) \equiv J(z)
$$

This indicates that the length of Phase II is an increasing function of the subsidy factor $z$.

$$
\frac{d J}{d z}=-\frac{1}{r \bar{P}_{u}}\left(\frac{d \bar{P}_{u}}{d z}\right)>0
$$


China's oil consumption during Phase II is

$$
\begin{gathered}
\int_{T^{u}}^{T^{w}} D_{E}^{c}\left(P_{t}\right) d t=M^{c} \int_{T^{u}}^{T^{w}}\left(A-P_{t}\right) d t=M^{c} \int_{T^{u}}^{T^{w}}\left(A-A^{-r\left(T^{w}-t\right)}\right) d t \\
=A M^{c}\left\{T^{w}-T^{u}-\frac{1}{r}\left[1-e^{-r\left(T^{w}-T^{u}\right)}\right]\right\} \\
=A M^{c}\left\{J(z)-\frac{1}{r}\left[1-e^{-r J(z)}\right]\right\} \equiv K(z)
\end{gathered}
$$

It is easy to verify that $K(z)$ is an increasing function: the higher is the biofuel subsidy factor in the U.S., the greater is China's total fossil fuel consumption in Phase II:

$$
\frac{d K}{d z}=A M^{c}\left(1-e^{-r J(z)}\right) \frac{d J}{d z}>0 .
$$

The inequality (31) is our first result concerning "carbon leakage" in a two-country world.

Let us turn to Phase I, in which fossil demands are positive in both countries. The total accumulated consumption of fossil fuels in Phase I must equal $\bar{R}-K(z)$ :

$$
\int_{0}^{T^{u}}\left[D^{u}\left(P_{t} ; z\right)+D_{E}^{c}\left(P_{t}\right)\right] d t=\bar{R}-K(z)
$$

where

$$
P_{t}=\bar{P}_{u} e^{-r\left(T^{u}-t\right)} \equiv \phi\left(\bar{P}_{u}(z), t, T^{u}\right)
$$

Define

$$
G\left(T^{u}, z, \bar{R}\right) \equiv \int_{0}^{T^{u}}\left[D^{u}(\phi ; z)+D_{E}^{c}(\phi)\right] d t-\bar{R}+K(z)
$$

The effect of an increase in the subsidy factor $z$ on the time $T^{u}$ at which the U.S.'s demand for fossil fuels vanishes is given by

$$
\frac{d T^{u}}{d z}=-\frac{\partial G / \partial z}{\partial G / \partial T^{u}}
$$

To determine the sign of this expression, we note that

$$
\partial G / \partial T^{u}=D_{E}^{c}\left(\bar{P}_{u}\right)+\int_{0}^{T^{u}}\left[\frac{\partial D^{u}}{\partial P_{t}}+\frac{\partial D_{E}^{c}}{\partial P_{t}}\right] \frac{\partial \phi}{\partial T^{u}} d t>0
$$


and

$$
\partial G / \partial z=\frac{d K}{d z}+\int_{0}^{T^{u}}\left[\left(\frac{\partial D^{u}}{\partial P_{t}}+\frac{\partial D_{E}^{c}}{\partial P_{t}}\right) \frac{\partial \phi}{\partial \bar{P}_{u}} \frac{d \bar{P}_{u}}{d z}+\frac{\partial D^{u}}{\partial z}\right] d t
$$

Using Hotelling's Rule, the integrand in (32) can be simplified to

$$
z^{\mu-1} \mu \beta e^{r(t-T)}\left[\frac{M_{c}+\mu \beta z^{\mu}\left[\left(P_{t}\right)^{\mu-1}-\left(\bar{P}_{u}\right)^{\mu-1}\right]}{1+\mu \beta z^{\mu}\left(\bar{P}_{u}\right)^{\mu-1}}\right], t \leq T^{u}
$$

which is positive if $M_{c}$ is big. Thus, if China's demand is significant enough, an increase in biofuel subsidy in the U.S. will lead to an earlier beginning of Phase II.

What about the effect of an increase in $z$ on the date where all fosil fuel stocks are exhausted, $T^{w}$ ? We must compute

$$
\frac{d T^{w}}{d z}=\frac{d T^{u}}{d z}+\frac{d J}{d z}
$$

This expression is negative if and only if

$$
\left(\partial G / \partial T^{u}\right) \frac{d J}{d z}<\frac{d K}{d z}+\int_{0}^{T^{u}}\left[\left(\frac{\partial D^{u}}{\partial P_{t}}+\frac{\partial D_{E}^{c}}{\partial P_{t}}\right) \frac{\partial \phi}{\partial \bar{P}_{u}} \frac{d \bar{P}_{u}}{d z}+\frac{\partial D^{u}}{\partial z}\right] d t
$$

i.e. if and only if

$-\int_{0}^{T^{u}}\left[\left(\frac{\partial D^{u}}{\partial P_{t}}+\frac{\partial D_{E}^{c}}{\partial P_{t}}\right) \frac{\partial \phi}{\partial \bar{P}_{u}} \frac{d \bar{P}_{u}}{d z}+\frac{\partial D^{u}}{\partial z}\right] d t+\frac{\partial D^{u}}{\partial z} d t-\left[\frac{d J}{d z}\right]\left[A M^{c}\left(1-e^{-r J(z)}\right)-\left(\partial G / \partial T^{u}\right)\right]<0$

We conclude that if the U.S.'s choke price is highly responsive to increases in biofuel subsidies, i.e. if $\frac{d \bar{P}_{u}}{d z}$ is sufficiently large in absolute value, then an increase in biofuel subsidy will bring the resource exhaustion date closer to the present

\section{Elaboration on the Proof of Proposition 3}

Consider the system

$$
\left[\begin{array}{l}
\dot{P} \\
\dot{Y}
\end{array}\right]=\left[\begin{array}{ll}
a_{11} & a_{12} \\
a_{21} & a_{22}
\end{array}\right]\left[\begin{array}{l}
P \\
Y
\end{array}\right]+\left[\begin{array}{l}
b_{1} \\
b_{2}
\end{array}\right]
$$

where $a_{11}=r, a_{12}=-r c_{1}, a_{21}=-(b+\beta z), a_{22}=0, b_{1}=-r c_{0}$ and $b_{2}=a$.In simpler notation,

$$
\dot{\mathbf{w}}=\mathbf{A} \mathbf{w}+\mathbf{b}
$$


where $\left(w_{1}, w_{2}\right) \equiv(P, Y)$, and $\operatorname{det} \mathbf{A}=a_{11} a_{22}-a_{12} a_{21}=-r c_{1}(b+\beta z)<0$. Let $\widetilde{\mathbf{w}}$ be the stationary point,

$$
\widetilde{\mathbf{w}}=-\mathbf{A}^{-1} \mathbf{b}
$$

Then

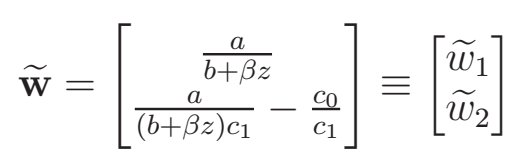

Define $\mathbf{x}$ as the deviation of $\mathbf{w}$ from $\widetilde{\mathbf{w}}$ :

$$
\mathbf{x} \equiv \mathbf{w}-\widetilde{\mathbf{w}}
$$

Let $\rho_{1}<0$ and $\rho_{2}>0$ be the characteristic roots,

$$
\begin{aligned}
\rho_{1,2} & =\frac{a_{11}+a_{22} \pm \sqrt{\left(a_{11}+a_{22}\right)^{2}-4\left(a_{11} a_{22}-a_{12} a_{21}\right)}}{2} \\
& =\frac{1}{2}(r \pm \sqrt{\Delta}) \text { where } \Delta \equiv r^{2}+4 r c_{1}(b+\beta z)
\end{aligned}
$$

Then the general solution is

$$
\left[\begin{array}{l}
x_{1}(t) \\
x_{2}(t)
\end{array}\right]=\left[\begin{array}{c}
h_{1} \\
-\left(a_{12}\right)^{-1}\left(a_{11}-\rho_{1}\right) h_{1}
\end{array}\right] \exp \left(\rho_{1} t\right)+\left[\begin{array}{c}
h_{2} \\
-\left(a_{12}\right)^{-1}\left(a_{11}-\rho_{2}\right) h_{2}
\end{array}\right] \exp \left(\rho_{2} t\right)
$$

where $h_{1}$ and $h_{2}$ are constants (to be determined using boundary conditions).

Define

$$
\begin{aligned}
& v_{1} \equiv-\left(a_{12}\right)^{-1}\left(a_{11}-\rho_{1}\right)=\frac{\rho_{1}-r}{-r c_{1}} \\
& v_{2} \equiv-\left(a_{12}\right)^{-1}\left(a_{11}-\rho_{2}\right)=\frac{\rho_{2}-r}{-r c_{1}}
\end{aligned}
$$

Setting $t=T$ in the matrix equation (33), and noting that have $x_{1}(T)=P_{T}-\widetilde{w}_{1}=0$ and $x_{2}(T)=Y_{T}-\widetilde{w}_{2}=\bar{R}-\widetilde{w}_{2} \equiv \bar{R}-\widetilde{Y}(z)$, we get two equations:

$$
\begin{gathered}
0=h_{1} \exp \left(\rho_{1} T\right)+h_{2} \exp \left(\rho_{2} T\right) \\
\bar{R}-\widetilde{Y}(z)=v_{1} h_{1} \exp \left(\rho_{1} T\right)+v_{2} h_{2} \exp \left(\rho_{2} T\right)
\end{gathered}
$$

Equation (36) gives

$$
h_{1}=-h_{2} \exp \left[\left(\rho_{2}-\rho_{1}\right) T\right]
$$


Substituting into equation (37) to get

$$
\bar{R}-\tilde{Y}(z)=-v_{1} h_{2} \exp \left(\rho_{2} T\right)+v_{2} h_{2} \exp \left(\rho_{2} T\right)
$$

Therefore

$$
h_{2}=\frac{\bar{R}-\tilde{Y}(z)}{\left(v_{2}-v_{1}\right) \exp \left(\rho_{2} T\right)}
$$

Setting $t=0$ in the matrix equation (33), we get two equations

$$
\begin{gathered}
P_{0}-\bar{P}(z)=h_{1}+h_{2} \\
Y_{0}-\tilde{Y}(z)=v_{1} h_{1}+v_{2} h_{2}
\end{gathered}
$$

Since $Y_{0}=0$, substituting (38) and (39) into (41) we get

$$
-\tilde{Y}(z)=\frac{\bar{R}-\tilde{Y}(z)}{\left(v_{2}-v_{1}\right) \exp \left(\rho_{2} T\right)}\left[v_{2}-v_{1} \exp \left[\left(\rho_{2}-\rho_{1}\right) T\right]\right]
$$

or

$$
\frac{\left(v_{2}-v_{1}\right) \exp \left(\rho_{2} T\right)}{v_{2}-v_{1} \exp \left[\left(\rho_{2}-\rho_{1}\right) T\right]}=\frac{\tilde{Y}(z)-\bar{R}}{\widetilde{Y}(z)}
$$

Now, using (34), (35) and (42)

$$
\frac{\left(\rho_{2}-\rho_{1}\right) \exp \left(\rho_{2} T\right)}{-\rho_{1}+\rho_{2} \exp \left[\left(\rho_{2}-\rho_{1}\right) T\right]}=\frac{\widetilde{Y}(z)-\bar{R}}{\widetilde{Y}(z)}
$$

Let

$$
\phi(T, z) \equiv \frac{\left(\rho_{2}-\rho_{1}\right)}{-\rho_{1} \exp \left[-\rho_{2} T\right]+\rho_{2} \exp \left[-\rho_{1} T\right]}
$$

The function $\phi(T, z)$ has the following properties: $\phi(0, z)=1, \partial \phi(T, z) / \partial T<0$ for all $T>0$, and

$$
\lim _{T \rightarrow \infty} \phi(T, z)=0
$$

It follows that the equation

$$
\phi(T, z)=\frac{\widetilde{Y}(z)-\bar{R}}{\widetilde{Y}(z)}
$$

has a unique solution $T>0$ (which depends on $z)$ 


\begin{tabular}{|c|c|c|c|c|c|}
\hline$T$ & 50 & 75 & $\mathbf{1 0 0}$ & 150 & 200 \\
\hline$\frac{d T}{d z}$ & -1.75 & -2.04 & $\mathbf{- 2 . 0 9}$ & -2.110 & -2.113 \\
\hline
\end{tabular}

Table 1: Effect of a Biofuel Subsidy on Exhaustion Date for Different Fossil Fuel Reserve Sizes

\begin{tabular}{|c|c|c|c|c|c|}
\hline$z$ & 0.5 & 0.75 & $\mathbf{1}$ & 1.5 & 2 \\
\hline$\frac{d T}{d z}$ & -6.6 & -3.43 & $\mathbf{- 2 . 0 9}$ & -0.99 & -0.56 \\
\hline
\end{tabular}

Table 2: Effect of a Biofuel Subsidy on Exhaustion Date for Different Initial Subsidy Levels

\begin{tabular}{|c|c|c|c|c|c|}
\hline$\varepsilon$ & 0.1 & 0.5 & $\mathbf{1}$ & 2 & 3 \\
\hline$\frac{d T}{d z}$ & -0.35 & -1.34 & $\mathbf{- 2 . 0 9}$ & -2.89 & -3.32 \\
\hline
\end{tabular}

Table 3: Effect of a Biofuel Subsidy on Exhaustion Date for Different Demand Elasticities of the Manufactured Good

\begin{tabular}{|c|c|c|c|c|c|}
\hline$\mu$ & 0.5 & 0.75 & $\mathbf{1}$ & 1.5 & 2 \\
\hline$\frac{d T}{d z}$ & $\mathbf{1 . 4 5}$ & -2.07 & $\mathbf{- 2 . 0 9}$ & -3.88 & -3.75 \\
\hline
\end{tabular}

Table 4: Effect of a Biofuel Subsidy on Exhaustion Date for Different Supply Elasticities of Biofuel

\begin{tabular}{|l|l|l|l|l|l|}
\hline $\begin{array}{l}\text { Cost sensitiv- } \\
\text { ity parameter }\end{array}$ & $\begin{array}{l}\text { Marginal ex- } \\
\text { traction cost } \\
\text { of the 'last } \\
\text { drop' }\end{array}$ & $\begin{array}{l}\text { Choke frice } \\
\text { of fuel when } \\
\mathrm{z}=1.2 / \mathrm{z}=1\end{array}$ & $\Delta T$ & $\Delta T / \Delta z$ & $\begin{array}{l}\text { Paradox/ No } \\
\text { Paradox }\end{array}$ \\
\hline 0 & 0.005 & $0.54 / 0.618$ & -0.270 & -1.35 & Paradox \\
\hline 0.0001 & 0.013 & $0.54 / 0.618$ & -0.176 & -0.88 & Paradox \\
\hline 0.0002 & 0.021 & $0.54 / 0.618$ & -0.077 & -0.39 & Paradox \\
\hline 0.0003 & 0.029 & $0.54 / 0.618$ & 0.025 & +0.13 & No Paradox \\
\hline 0.0005 & 0.045 & $0.54 / 0.618$ & 0.244 & +1.22 & No Paradox \\
\hline
\end{tabular}

Table 5: Parameter Values for the Weak Green Paradox 


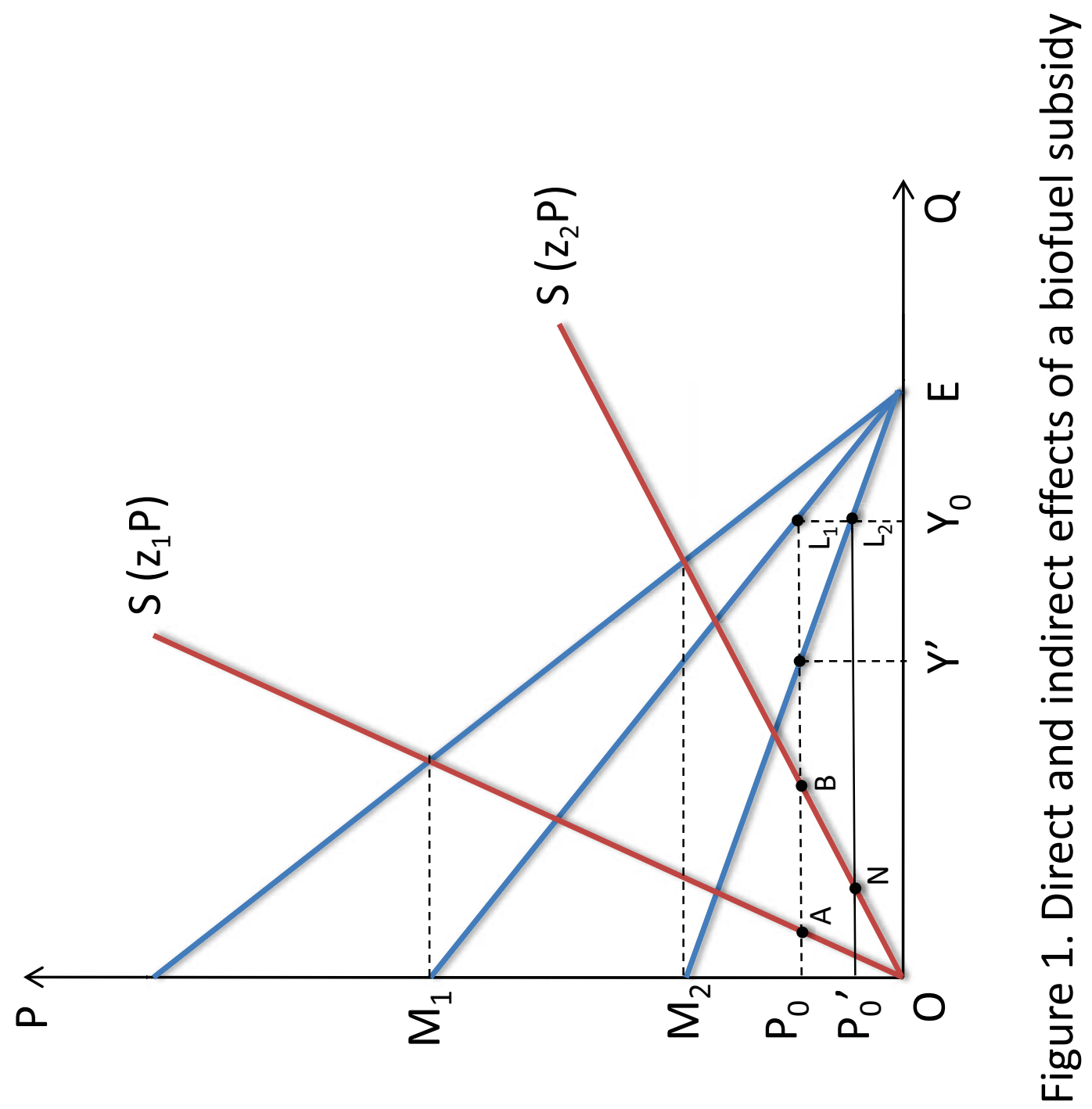




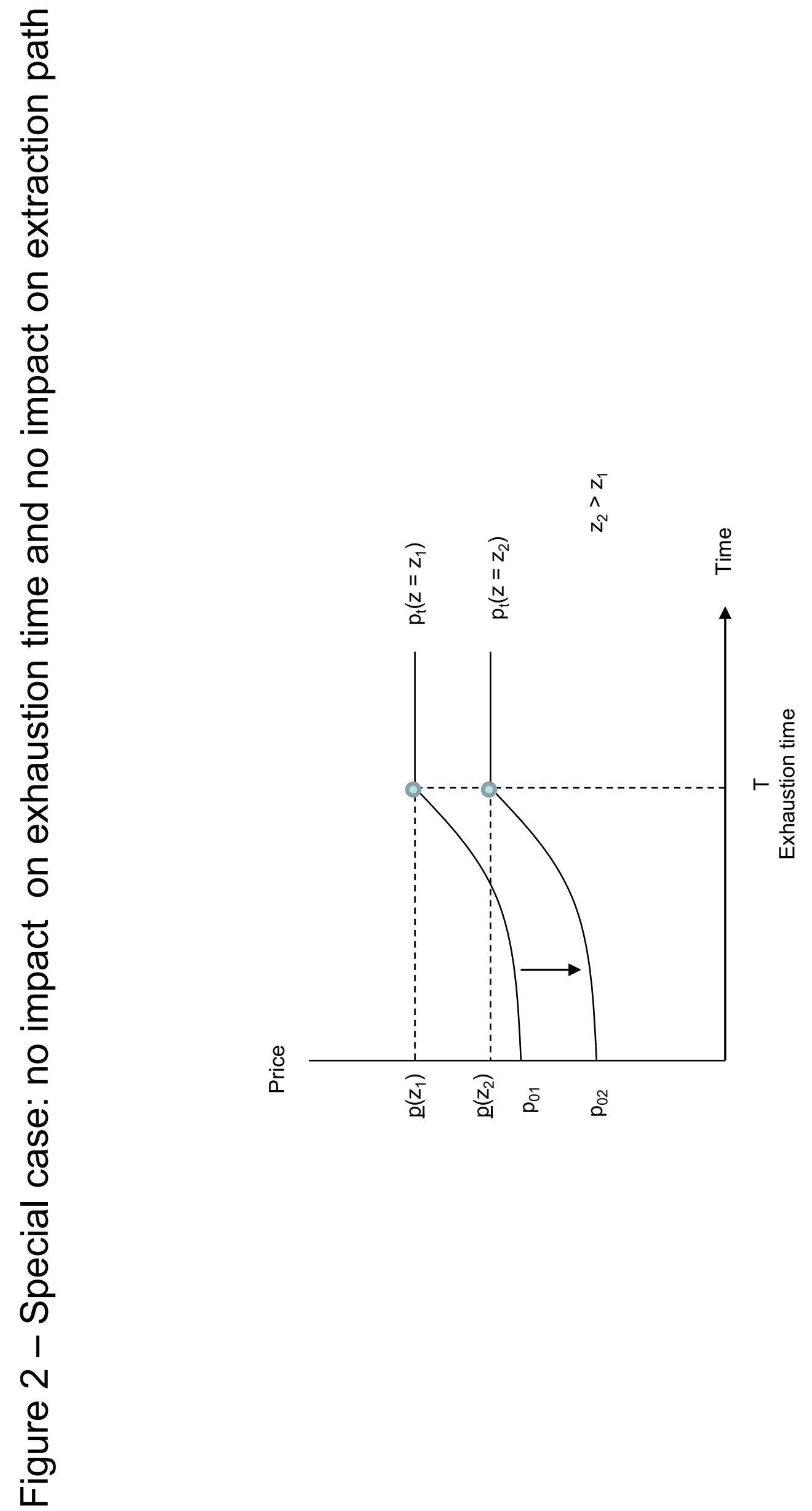




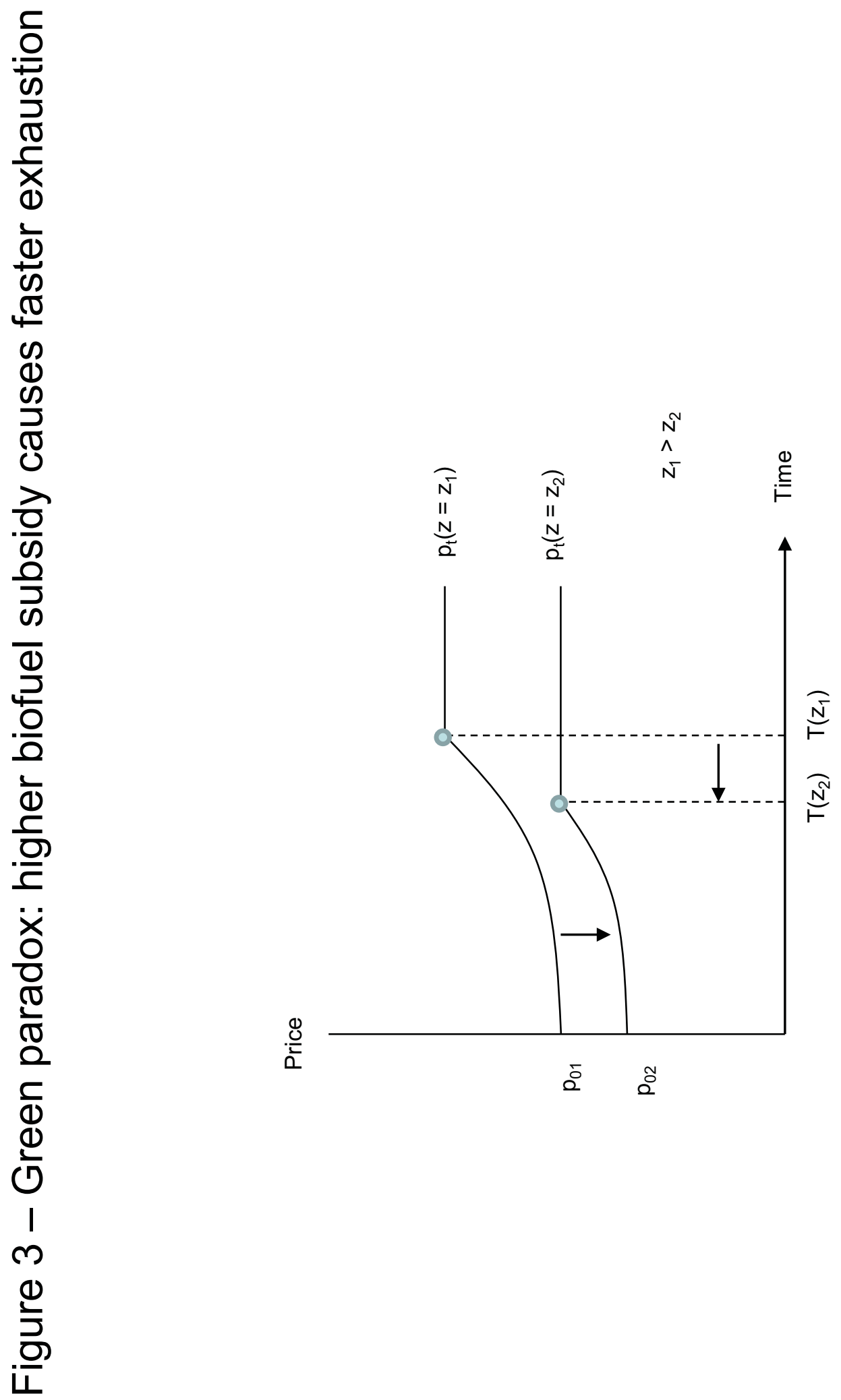

